\title{
Aqueous Phase Photo-oxidation of Brown Carbon Nitrophenols: Reaction Kinetics, Mechanism, and Evolution of Light Absorption
}

\author{
Rachel F. Hems, Jonathan P. D. Abbatt
}

Version Post-print/Accepted Manuscript

\begin{abstract}
Citation Hems, R.F., Abbatt, J.P.D., 2018. Aqueous Phase Photo-oxidation of (published version) Brown Carbon Nitrophenols: Reaction Kinetics, Mechanism, and Evolution of Light Absorption. ACS Earth Space Chem. https://doi.org/10.1021/acsearthspacechem.7b00123.

Copyright / License This document is the Accepted Manuscript version of a Published Work that appeared in final form in ACS Earth and Space Chemistry, copyright (C) American Chemical Society after peer review and technical editing by the publisher. To access the final edited and published work see https://pubs.acs.org/doi/10.1021/acsearthspacechem.7b00123.
\end{abstract}

How to cite TSpace items

\begin{abstract}
Always cite the published version, so the author(s) will receive recognition through services that track citation counts, e.g. Scopus. If you need to cite the page number of the author manuscript from TSpace because you cannot access the published version, then cite the TSpace version in addition to the published version using the permanent URI (handle) found on the record page.
\end{abstract}

This article was made openly accessible by $U$ of $T$ Faculty. Please tell us how this access benefits you. Your story matters. 


\section{Aqueous Phase Photo-oxidation of Brown Carbon}

2 Nitrophenols: Reaction Kinetics, Mechanism, and

3 Evolution of Light Absorption

4 Rachel F. Hems*, Jonathan P. D. Abbatt

5 Department of Chemistry, University of Toronto, 80 St. George Street, Toronto, ON, M5S 3H6,

6 Canada

7 ABSTRACT

8 Light absorbing organic aerosol particles, referred to as brown carbon, are geographically

9 widespread and can have an important climate impact through the absorption of solar radiation.

10 Recent studies, both in the laboratory and the field, have shown that brown carbon aerosols can be

11 bleached of their color by direct photolysis and photo-oxidation reactions on the timescale of hours

12 to days. However, the photo-oxidation of nitrophenol molecules, which are colored compounds

13 often associated with biomass burning organic aerosol, show an enhancement in light absorption

14 before the color is lost. This study investigates the mechanism of color enhancement and the fate

15 of three nitrophenol compounds, specifically nitrocatechol, nitroguaiacol, and dinitrophenol, in

16 aqueous aerosol using online aerosol chemical ionization mass spectrometry (aerosol-CIMS). The

17 second order rate constants for the three nitrophenols with $\mathrm{OH}$ radicals in the aqueous phase at $\mathrm{pH}$ 
$187(298 \mathrm{~K})$, were determined to be $5 \times 10^{9} \mathrm{M}^{-1} \mathrm{~s}^{-1}, 5.2 \times 10^{9} \mathrm{M}^{-1} \mathrm{~s}^{-1}$, and $3.7 \times 10^{9} \mathrm{M}^{-1} \mathrm{~s}^{-1}$ for

19 nitrocatechol, nitroguaiacol, and dinitrophenol, respectively. For a representative aqueous $\mathrm{OH}$

20 concentration, these rate constants correspond to an aqueous lifetime with respect to $\mathrm{OH}$ on the

21 order of hours. While the nitrophenol molecules react rapidly with $\mathrm{OH}$, the initial products, which

22 are functionalized by additional electron-donating $\mathrm{OH}$ groups, likely lead to the observed

23 absorption increase in the visible range. Further photo-oxidation fragments the aromatic structure

24 to produce smaller, highly oxygenated molecules which no longer absorb strongly at visible

25 wavelengths. These products include furoic acid, glyoxylic acid, malonic acid, oxalic acid, and

26 isocyanic acid. All three nitrophenols investigated formed similar products during photo-

27 oxidation, suggesting that these results could be generalized to this larger class of compounds.

28 Keywords: brown carbon aerosol, biomass burning, photo-bleaching, aqueous oxidation, aerosol

29 aging

30 INTRODUCTION

31 Light absorbing organic aerosol particles in the atmosphere, known as brown carbon $(\mathrm{BrC})$, are

32 increasingly studied due to their various sources, complex composition, and prevalence in the

33 atmosphere. Similar to black carbon, $\mathrm{BrC}$ can give rise to a positive radiative forcing through the

34 aerosol direct effect, especially in the upper troposphere. ${ }^{1}$ The semi-direct effect observed with

35 black carbon, where warming can decrease relative humidity and increase cloud droplet

36 evaporation, may also enhance the positive radiative forcing potential of $\mathrm{BrC}^{2}$ However, the

37 magnitude of the warming effect of $\mathrm{BrC}$ is still uncertain and has only recently been investigated

38 in models. ${ }^{1,3-6}$ A major primary source of $\mathrm{BrC}$ is biomass and fossil fuel burning. ${ }^{7}$ Secondary

39 production can also occur through aqueous chemistry between ammonia or amines and 
40 aldehydes, ${ }^{8-10}$ as well as photo-oxidation of phenolic compounds. ${ }^{11,12}$ Nitrophenols are a class of

41 light absorbing compounds often detected in significant concentrations $\left(10 \mathrm{~s} \mathrm{of} \mathrm{ng} \mathrm{m}^{-3}\right)$ in

42 biomass burning BrC. ${ }^{13,14}$ These phenolic compounds are derived from pyrolysis of lignin, ${ }^{14}$ but

43 can also be formed by photo-oxidation of anthropogenic pollutants such as xylene ${ }^{15}$ and

44 toluene. ${ }^{16}$ Nitrophenols are readily water soluble and have been measured in cloud, fog, and rain

45 water at concentrations of up to tens of ug $\mathrm{L}^{-1} \cdot{ }^{13}$

46 The magnitude of the climate impact of $\mathrm{BrC}$ depends in part on the atmospheric lifetime of the

47 specific light-absorbing compounds. Forrister et al. followed a biomass burning plume

48 downwind from the source and found a significant decrease in the $\mathrm{BrC}$ absorption with

49 photochemical aging. ${ }^{17}$ Photo-bleaching of $\mathrm{BrC}$ has been observed in a number of studies both in

50 the laboratory and in field measurements. ${ }^{18-22}$ Analysis of aged biomass burning BrC by Di

51 Lorenzo et al. found no detectable nitrophenol compounds, and instead concluded that the

52 majority of the light absorbing compounds had very large molecular weights $(>1000 \mathrm{amu}) .^{23,24}$

53 Nitrophenols are reactive towards direct photolysis ${ }^{25-28}$ and photo-oxidation ${ }^{29-31}$ in the gas phase

54 and the condensed phase and therefore it is likely that atmospheric aging decreases their

55 concentration. However, to account for detection of nitrophenols far from primary sources,

56 aqueous formation of nitrophenols has also been proposed. ${ }^{13}$

57 Zhao et al. noted a striking feature in the aqueous $\mathrm{OH}$ oxidation of nitrophenol compounds

58 during the early part of the reaction, the absorption in the visible range (and specifically at 420

$59 \mathrm{~nm}$ ) increased. ${ }^{18}$ This suggests that the reaction products were just as, if not more, strongly

60 absorbing than the parent nitrophenol molecule. This feature of enhanced absorption has also

61 been observed more generally from atmospheric processing of biomass burning aerosol. ${ }^{32,33}$ At

62 longer $\mathrm{OH}$ oxidation times, the absorbance at all wavelengths was observed to decrease 
63 significantly. The formation of light-absorbing products could extend the lifetime of $\mathrm{BrC}$

64 absorption even after the nitrophenol has reacted. However, this mechanism has not been

65 previously examined.

66 This study investigates the photo-oxidation of three commonly detected nitrophenol compounds

67 using the aerosol-CIMS: nitrocatechol, nitroguaiacol, and dinitrophenol (structures shown in

68 Figure 1). The second-order rate constants of their reaction with $\mathrm{OH}$, the change in UV-visible

69 light absorption, and mechanistic insights are presented for all three molecules. These

70 measurements provide a better understanding of the aging of this class of $\mathrm{BrC}$ compounds and

71 how their light absorption changes as a function of that aging.<smiles>COc1ccc([N+](=O)[O-])cc1O</smiles>

Nitroguaiacol<smiles>O=[N+]([O-])c1cccc(O)c1O</smiles>

Nitrocatechol<smiles>O=[N+]([O-])c1ccc(O)c([N+](=O)[O-])c1</smiles>

Dinitrophenol

73 Figure 1. Chemical structures of the nitrophenols examined in this study: nitroguaiacol,

74 nitrocatechol, and dinitrophenol.

\section{Photo-oxidation of nitrophenol compounds}

77 Photo-oxidation reactions were carried out in a Pyrex atomizer bottle with a $254 \mathrm{~nm}$ mercury

78 lamp (UVP, constructed to remove the $185 \mathrm{~nm}$ line to avoid generating ozone) inserted inside the

79 reaction solution ( $150 \mathrm{~mL}$ total volume). Solutions of 4-nitrocatechol, 2-methoxy-5-nitrophenol 
80 (5-nitroguaiacol), and 2,4-dinitrophenol (Sigma-Aldrich) were supplied from stock solutions,

81 made with purified water $(18.2 \mathrm{M} \Omega \mathrm{cm})$, to obtain a concentration of $30 \mu \mathrm{M}$ in the reaction

82 vessel. This concentration of nitrophenol was used to simulate the upper end of concentrations

83 measured in biomass burning impacted cloud water. ${ }^{34} \mathrm{H}_{2} \mathrm{O}_{2}(\geq 30 \% \mathrm{wt}$, Sigma-Aldrich) as the

$84 \mathrm{OH}$ precursor, was added to obtain a concentration of $1 \mathrm{mM}$. Upon UV irradiation, this

85 concentration of $\mathrm{H}_{2} \mathrm{O}_{2}$ generated an $\mathrm{OH}$ radical steady state concentration of approximately (3-

$864) \times 10^{-13} \mathrm{M}$ in solution (see supporting information for detailed calculation). For all photo-

87 oxidation experiments, reaction time $=0$ is defined as the time that the lamp was turned on,

88 which initiated $\mathrm{OH}$ radical generation. The $\mathrm{pH}$ of the solutions was unbuffered and was generally

89 between $6.5-7.5$ throughout the reaction. The pKa for 4-nitrocatechol $(6.87)^{35}$, 5-nitroguaiacol

90 (estimated from 4-nitroguaiacol ${ }^{35} \sim 7$ ), and 2,4-dinitrophenol $(4.04)^{35}$ indicate that nitrocatechol

91 and nitroguaiacol are likely to be present as both the ionized and non-ionized form, while

92 dinitrophenol is expected to be primarily ionized under the experimental conditions. Any

93 differences in the chemistry of the nitrophenol and corresponding nitrophenolate were not

94 isolated in this study. The starting temperature of the solutions was unregulated $\left(24 \pm 2^{\circ} \mathrm{C}\right)$ with

95 some warming from the UV lamp to reach temperatures of up to $30 \pm 1^{\circ} \mathrm{C}$, as measured by a

96 thermometer after 60 minutes.

\section{Aerosol-CIMS}

98 An aerosol time-of-flight chemical ionization mass spectrometer (TOF-CIMS, Aerodyne

99 Research Inc.) was employed for online analysis of reaction solutions during photo-oxidation.

100 The aerosol-CIMS setup and operation has been described previously, ${ }^{36-39}$ but will be briefly

101 summarized here. The experimental set-up is illustrated in Figure S1. The reaction solution was

102 atomized by a constant output atomizer (TSI, model 3076) using compressed air as the carrier 
103 gas (Linde, Air Grade Zero 0.1) at a flow rate of $3 \mathrm{~L} \mathrm{~min}^{-1}$. The atomizer output was diluted with

104 a $1.5 \mathrm{~L} \mathrm{~min}^{-1}$ flow of nitrogen and directed through a Siltek-coated stainless steel tube (1/4 in.

$105 \mathrm{OD}, 70 \mathrm{~cm}$ long, VWR) heated to $150{ }^{\circ} \mathrm{C}$. The volatilized organic compounds were introduced

106 into the TOF-CIMS, which had a sample flow rate of $2.0 \mathrm{~L} \mathrm{~min}^{-1}$ (set by a critical orifice).

107 The reagent ion used in this study was the acetate anion $\left(\mathrm{CH}_{3} \mathrm{C}(\mathrm{O}) \mathrm{O}^{-}\right)$due to its sensitivity

108 towards acidic organic compounds. ${ }^{40}$ Acetate was generated by a flow of $10 \mathrm{sccm}$ of nitrogen

109 through the headspace of acetic anhydride (Sigma-Aldrich) in a stainless steel bottle at room

110 temperature, which was then diluted by $2.2 \mathrm{~L} \mathrm{~min}^{-1}$ of nitrogen. The reagent ion flow passed

111 through a ${ }^{210} \mathrm{Po}$ radioactive cell (NRD, P-2021) at a flow of $2 \mathrm{~L} \mathrm{~min}^{-1}$ (set by a critical orifice) to

112 generate acetate ions in the ion-molecule reaction (IMR) chamber of the CIMS. The acetate ion

113 was thought to ionize primarily by proton abstraction, however, other ionization mechanisms

114 have recently been identified. ${ }^{41}$ The pressures in the IMR and short segmented quadrupole ion-

115 transmission (SSQ) regions were set to $100 \pm 5$ mbar and 2.0 \pm 0.1 mbar respectively. A strong-

116 field mode is used to prevent formation of acetate clusters (detailed voltage parameters in Table

117 S1), where the [acetate + acetic acid] cluster to acetate ratio is approximately 0.001 . The mass

118 spectrometer was operated in V-mode and data were acquired at $1 \mathrm{~s}$ time resolution. Data

119 processing was performed in Igor Pro (WaveMetrics Inc. Version 6.37) running Tofware

120 (Aerodyne Research Inc. Version 2.5.7). A mass accuracy of $\pm 5 \mu \mathrm{Th} \mathrm{Th}^{-1}$ (ppm) and mass

121 resolving power of 3500 - 4500 were obtained over the relevant $m / z$ range. All data are presented

122 as the signal of the ion of interest normalized to the signal of the acetate reagent ion. 
126 Measurement of the UV-Vis absorbance of the reaction solution ( $2 \mathrm{~mL}$ aliquots) throughout the

127 photo-oxidation experiments was performed offline on the same day as collection. A liquid

128 waveguide capillary UV-Vis spectrometer (World Precision Instruments) was used, with a

129 deuterium tungsten halogen light source (DT-Mini-2, Ocean Optics) and a temperature

130 controlled UV-Vis spectrometer (USB2000+, Ocean Optics). This instrument has a long

131 effective path length $(50 \mathrm{~cm})$, which results in high sensitivity. The spectrometer measures

132 absorbance across a large spectral window, from 230 to $850 \mathrm{~nm}$. SpectraSuite software (Ocean

133 Optics) was used to record data.

\section{Relative Rate Method}

135 The second order rate constant of each nitrophenol compound reacting with $\mathrm{OH}$ radicals was

136 determined with the relative rate method. The decay of each nitrophenol compound and the

137 decay of a compound with a known second order rate constant with $\mathrm{OH}$ were measured with the

138 aerosol-CIMS. In this study, benzoic acid (Sigma-Aldrich, $30 \mu \mathrm{M}$ ), which has a second order

139 rate constant with $\mathrm{OH}$ of $(5.9 \pm 0.5) \times 10^{9} \mathrm{M}^{-1} \mathrm{~s}^{-1}$ at $\mathrm{pH} 7$, was used as the reference compound. ${ }^{42}$

140 Assuming the only loss process is reaction with $\mathrm{OH}$ radicals, the integrated rate law for the

141 nitrophenol can be substituted into the integrated rate law for benzoic acid and the following

142 relationship is obtained:

$$
\ln \left(\frac{[X]_{0}}{[X]_{t}}\right)=\frac{k_{X}^{I I}}{k_{B A}^{I I}} \times \ln \left(\frac{[B A]_{0}}{[B A]_{t}}\right)
$$

144 In equation $1,[\mathrm{X}]_{0}$ and $[\mathrm{X}]_{\mathrm{t}}$ represents the nitrophenol signal measured at time zero and time $t$

145 after $\mathrm{OH}$ reaction was initiated, respectively. The signal of benzoic acid (BA), the reference 
146 compound, is also measured at time zero and time $t$ during $\mathrm{OH}$ reaction. The second order rate

147 constants for the nitrophenol compound and benzoic acid are denoted as $k_{X}^{I I}$ and $k_{B A}^{I I}$ respectively.

\section{RESULTS AND DISCUSSION}

149 UV-Vis Absorption Spectra

150 It has been reported that nitrocatechol and other nitrophenols undergo a change in absorbance

151 during aqueous $\mathrm{OH}$ oxidation in the wavelength region between $410-460 \mathrm{~nm} \cdot{ }^{18}$ Similarly, we

152 have observed an enhancement in absorptivity in this region, then subsequent reduction in

153 absorptivity during aqueous $\mathrm{OH}$ oxidation of nitrocatechol, nitroguaiacol, and dinitrophenol.

154 Figure 2(A) shows how the nitrocatechol UV-Vis absorption spectrum changes as $\mathrm{OH}$ oxidation

155 time increases. For clarity, the absorption at $420 \mathrm{~nm}$ is plotted on the right, showing the

156 maximum absorption occurring within the first 10 minutes of photo-oxidation time. This is

157 plotted alongside the control reactions, including direct photolysis (purple) and dark reaction

158 with $\mathrm{H}_{2} \mathrm{O}_{2}$ (pink), which show negligible changes to the absorbance over an equivalent

159 timescale. The evolution of absorbance in the visible and near-visible range indicates that there is

160 chemistry occurring which initially enhances the absorption and then degrades the chromophoric

161 compounds resulting in a colorless solution.

162 The absorption evolution with photo-oxidation of nitroguaiacol and dinitrophenol are shown in

163 Figure 2(B) and (C), respectively. Again, the corresponding absorbance during the control

164 reactions for nitroguaiacol and dinitrophenol are plotted alongside on the right in Figure 2(B)

165 and (C) respectively, and show negligible change over the reaction timescale. In the case of

166 nitroguaiacol, the absorption enhancement at $420 \mathrm{~nm}$ is even greater than for nitrocatechol, and 
167 the enhanced absorption extends longer into the reaction time. Dinitrophenol has a slightly

168 different original UV-Vis absorption profile compared to nitrocatechol and nitroguaiacol, so the

169 absorption change over time was instead monitored at $460 \mathrm{~nm}$. This molecule also goes through

170 a significant absorption enhancement during photo-oxidation before all absorption in this range

171 is lost. Not only does the absorption change in these three molecules (and likely all nitroaromatic

172 compounds), indicate that interesting oxidation chemistry is occurring in the atmospheric

173 aqueous phase, it also has consequences for the longevity of this type of $\mathrm{BrC}$ compound, which

174 ultimately affects the radiative forcing potential of these particles. To emphasize the effect that

175 the increase in absorption has on the relative amount of sunlight absorbed, the product of the

176 absorption (nitrophenol concentration of $5 \mu \mathrm{M}$, Figure S2) and estimated solar power flux as a

177 function of wavelength was calculated and integrated from $300-700 \mathrm{~nm}$, shown in Figure $\mathbf{S 3}$

178 for each nitrophenol molecule as a function of photo-oxidation time. The corresponding relative

179 increase in this value during the first few minutes of the reaction reinforces that the increase in

180 the absorption of these molecules during photo-oxidation can significantly increase the overall

181 absorbed sunlight. 
182
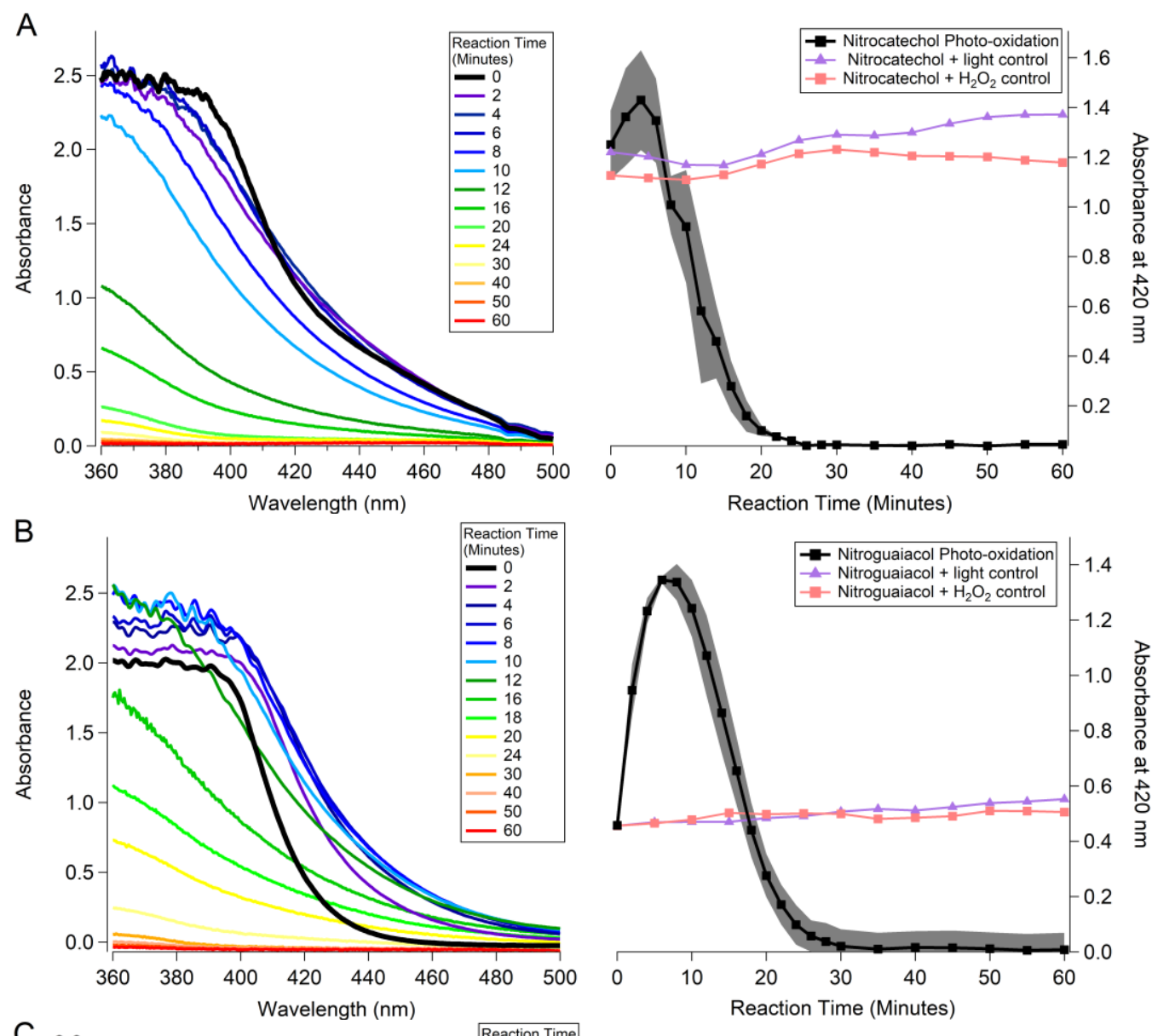

183
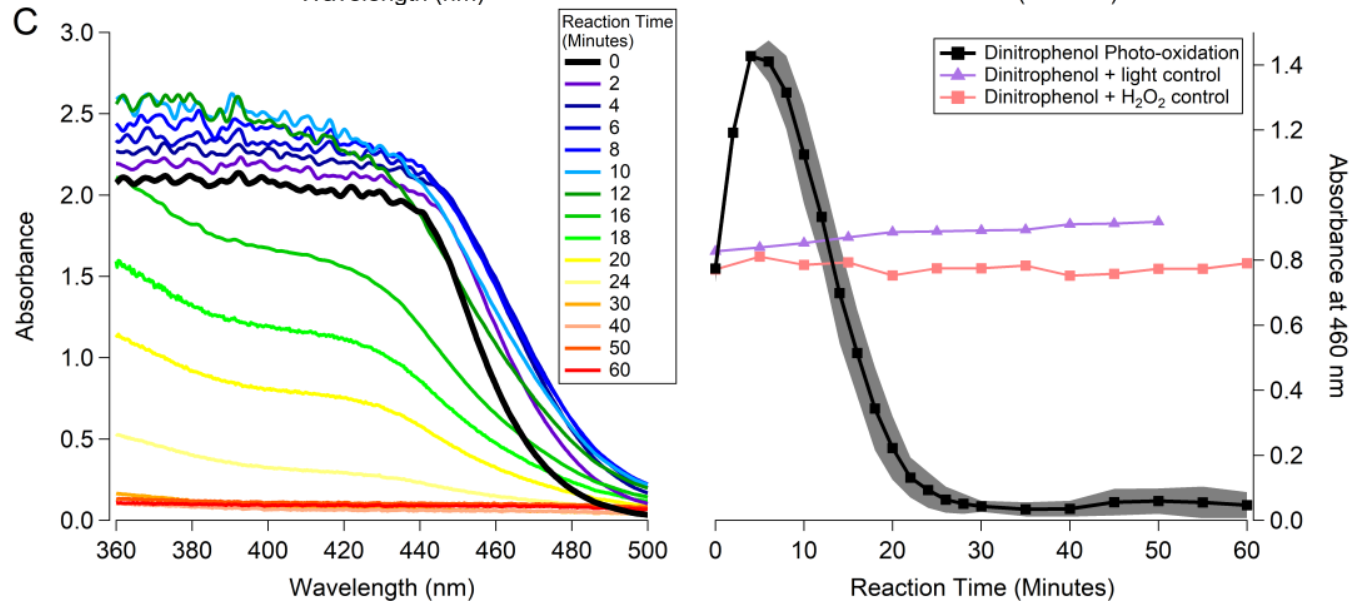

185 Figure 2. Absorption spectra of nitrocatechol (A), nitroguaiacol (B), and dinitrophenol (C) during photo-oxidation. On the left panel is the full spectrum taken at sequential time steps during the

187 reaction. On the right panel, the absorbance at $420 \mathrm{~nm}$ (460 nm for dinitrophenol) is plotted as a

188 function of reaction time. Shading indicates the standard deviation between multiple experiments.

189 The control reactions including photolysis of the nitrophenol (+ light control, purple) and dark

190 reaction with $\mathrm{H}_{2} \mathrm{O}_{2}\left(+\mathrm{H}_{2} \mathrm{O}_{2}\right.$ control, pink) are plotted for reference. 


\section{Relative Rate Kinetics}

192 As discussed above, the relative rate method was used to determine the second order rate

193 constant for the reaction of each nitrophenol molecule with hydroxyl radicals in the aqueous phase

194 at $\mathrm{pH}$ 7. All three nitrophenols decay rapidly following the initiation of hydroxyl radical production

195 (at $\mathrm{t}=0)$ (Figure S4). Equation 1 was used to determine the second order rate constant for each

196 nitrophenol molecule from the slope of the relative rate plots shown in Figure 3.

197 The calculated second order rate constants are summarized in Table 1. The reported error includes

198 the propagation of the uncertainty in the second order rate constant for benzoic acid ( $\left.\mathrm{K}^{\mathrm{II}} \mathrm{BA}\right)$ and 1

199 standard deviation in the linear fit of the slope in the relative rate plots (Figure 3). The

200 nitroguaiacol and dinitrophenol kinetics experiments were carried out with the benzoic acid

201 reference compound in the same solution, as is generally done for relative rate kinetics. However,

202 for nitrocatechol, interference at the same $\mathrm{m} / \mathrm{z}$ was observed when benzoic acid was added to the

203 same solution. The nitrocatechol rate constant was therefore calculated from experiments where

204 nitrocatechol and benzoic acid were measured separately, but under the same conditions. This

205 introduces additional error into the measurement of the nitrocatechol second order rate constant.

206 This rate constant for nitrocatechol obtained from using benzoic acid as the reference was

207 measured to be $(5.9 \pm 0.5) \times 10^{9} \mathrm{M}^{-1} \mathrm{~s}^{-1}$. To confirm this measurement, the nitrocatechol rate

208 constant was also measured with levoglucosan as the reference compound, shown in Figure S5

209 and discussed in the supporting information. The rate constant for nitrocatechol with levoglucosan

210 as the reference was measured to be $(4.4 \pm 0.4) \times 10^{9} \mathrm{M}^{-1} \mathrm{~s}^{-1}$. To represent the variability in the

211 nitrocatechol rate constant measurement, we propose a second order rate constant of $(5 \pm 1) \times 10^{9}$

$212 \mathrm{M}^{-1} \mathrm{~s}^{-1}$. 
213 The second order rate constant for the $\mathrm{OH}$ reaction with nitroguaiacol was measured to be $(5.2 \pm$

$2140.4) \times 10^{9} \mathrm{M}^{-1} \mathrm{~s}^{-1}$. To the best of our knowledge, this is the first published report of an aqueous

215 phase rate constant for reaction of $\mathrm{OH}$ radicals with nitrocatechol and nitroguaiacol. The rate

216 constant for reaction of $\mathrm{OH}$ and dinitrophenol has been measured previously to be $(2.3 \pm 0.4) \times$

$21710^{9} \mathrm{M}^{-1} \mathrm{~s}^{-1}$ at $\mathrm{pH} 2.5^{43}$ and $(5.7 \pm 0.6) \times 10^{9} \mathrm{M}^{-1} \mathrm{~s}^{-1}$ at $\mathrm{pH} 7 .{ }^{44}$ The rate constant determined from

218 this experiment for dinitrophenol, $(3.7 \pm 0.3) \times 10^{9} \mathrm{M}^{-1} \mathrm{~s}^{-1}$ at $\mathrm{pH} 7$, is in good agreement with these 219 previous studies.

220 The lifetime of each molecule, shown in Table 1, is calculated based on the rate constants

221 determined here and an aqueous phase $\mathrm{OH}$ concentration of $1 \times 10^{-14} \mathrm{M}$, which has been

222 measured to be at the upper range of $\mathrm{OH}$ concentrations in cloud and fog water. ${ }^{45-47}$ At this

223 concentration, the lifetime in aqueous atmospheric droplets is on the order of 7.5 hours or less for

224 all three nitrophenol molecules. When compared to the rate of gas phase $\mathrm{OH}$ oxidation (Table

225 S2) and taking into account typical $\mathrm{OH}$ concentrations and liquid water content, aqueous phase

$226 \mathrm{OH}$ oxidation is estimated to be the dominant sink for all three nitrophenols in cloud conditions

227 (discussion in supporting information and Table S3). However, this conclusion will depend on

228 the time spent in cloud, cloud and gas phase $\mathrm{OH}$ concentrations, as well as aerosol liquid water. 

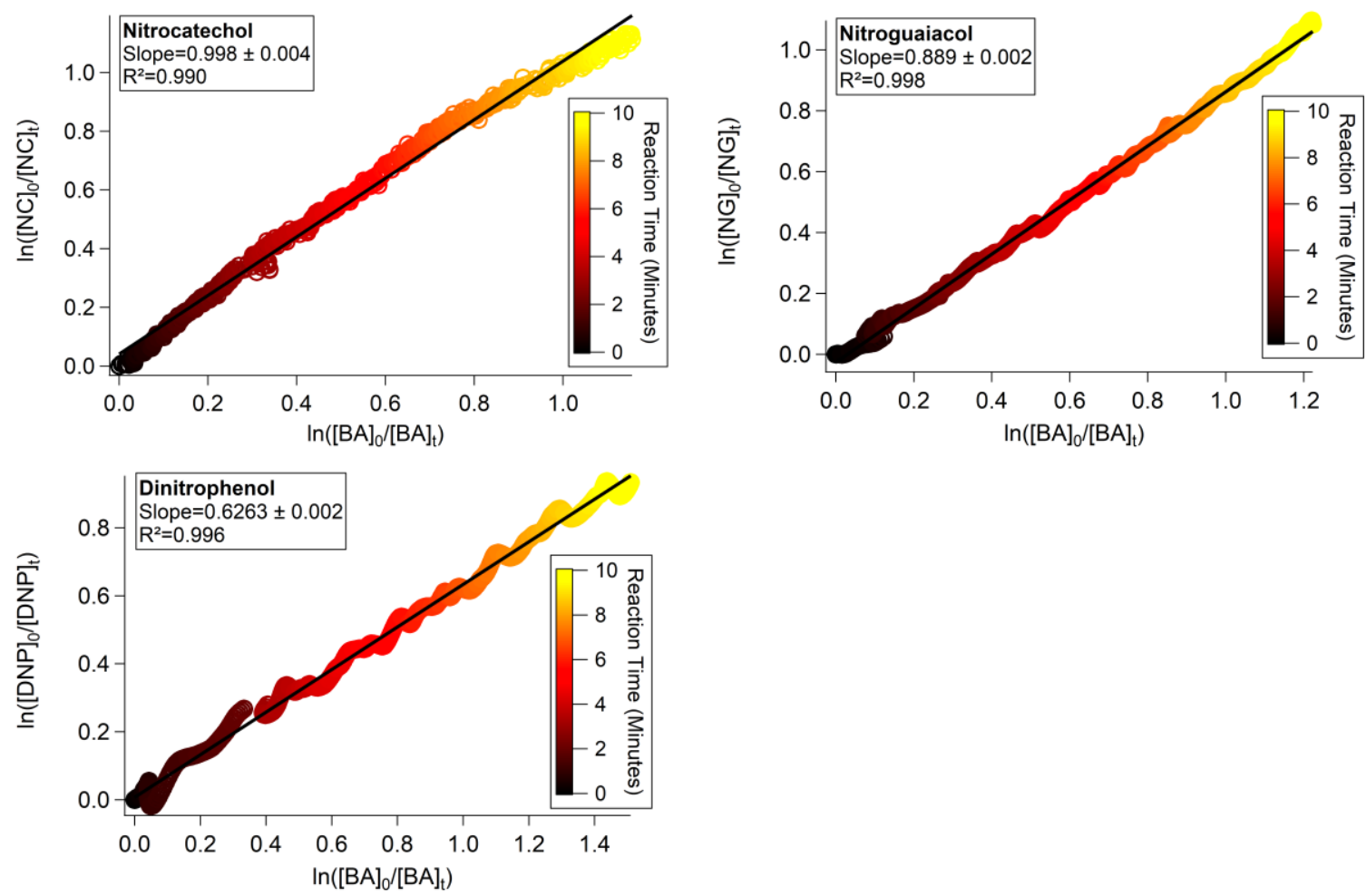

232 Figure 3. Relative kinetics plot of nitrocatechol, nitroguaiacol, and dinitrophenol with reference

233 compound benzoic acid, according to Equation 1. Color scale corresponds to $\mathrm{OH}$ reaction time.

234 Table 1. Summary of nitrophenol second order rate constants and calculated aqueous phase 235 lifetime with respect to $\mathrm{OH}$ oxidation at $\mathrm{pH}$ 7. Error on the second order rate constants is 236 propagated from the uncertainty in the second order rate constant for benzoic acid and 1 standard 237 deviation of the linear fits from Figure 3.

\begin{tabular}{|c|c|c|}
\hline Molecule & $\begin{array}{c}\mathbf{k}^{\mathrm{II}} \mathbf{O H} \times \mathbf{1 0}^{\mathbf{9}}\left(\mathbf{M}^{-\mathbf{1}} \mathbf{s}^{\mathbf{- 1}}\right) \\
\text { Error is based on 1 standard } \\
\text { deviation of linear fit and } \\
\text { uncertainty in k }{ }^{\mathrm{II}} \mathrm{BA}\end{array}$ & $\begin{array}{c}\text { Lifetime (hours) } \\
\text { Assuming }[\mathrm{OH}]=1 \times 10^{-14} \mathbf{M}\end{array}$ \\
\hline 4-Nitrocatechol & $5 \pm 1^{*}$ & 5.7 \\
\hline 5-Nitroguaiacol & $5.2 \pm 0.4$ & 5.3 \\
\hline 2,4-Dinitrophenol & $3.7 \pm 0.3$ & 7.5 \\
\hline
\end{tabular}

* See discussion in Relative Rate Kinetics section regarding the uncertainty on this value. 
240 The formation of the photo-oxidation products of each nitrophenol molecule were monitored

241 throughout the reaction by the aerosol-CIMS with acetate reagent ion. Approximately 50 distinct

242 reaction products were identified by mass spectrometry as anions in each reaction (summarized

243 in Table S4). No direct photolysis of the nitrophenols was observed under these conditions for

244 the duration of the reaction (Figure S6). OH oxidation of chemically similar structures (benzene,

245 phenol, and nitrophenol) has been studied previously in the aqueous phase. ${ }^{48-50}$ Those studies

246 report that a common first oxidation step is the addition of a hydroxyl group to the aromatic ring.

247 Oligomers are noted to arise under high concentration conditions, such as in the aqueous phase

$248 \mathrm{OH}$ oxidation of $\mathrm{mM}$ and higher concentration solutions of small dicarbonyls, ${ }^{51,52}$ as well as at

$249100 \mu \mathrm{M}$ concentrations of phenols. ${ }^{49,53}$ With the nitrophenol concentrations used in this

250 experiment $(30 \mu \mathrm{M})$, oligomers were not observed to form.

251 Photo-oxidation of the more substituted nitrophenols explored in this study (nitrocatechol,

252 nitroguaiacol, and dinitrophenol) have not been previously examined. The primary goal of

253 elucidating the photo-oxidation mechanism is to identify possible absorbing species that may

254 cause the observed enhancement in absorption in the visible light range (Figure 2).

255 Identification of the breakdown pathway and final fate of the nitrophenol molecules is the

256 secondary goal of elucidation of the photo-oxidation mechanism. For simplicity, the following

257 discussion will focus on nitrocatechol. However, the mechanism for nitroguaiacol and

258 dinitrophenol are analogous, and the formation of similar functionalized and fragmented

259 products is included in the supporting information (Figures S7 - S10). 
262 Nitrocatechol was detected as the negative ion at $m / z 154\left(\mathrm{C}_{6} \mathrm{H}_{4} \mathrm{NO}_{4}{ }^{-}\right)$. As the nitrocatechol

263 signal decays following the initiation of $\mathrm{OH}$ oxidation, functionalized products with molecular

264 formulae corresponding to increases in the number of oxygen atoms were observed to peak

265 within the first 8 minutes of the reaction, as shown in Figure 4 (all reported molecular formulae

266 refer to the neutral molecule). These compounds have been identified by the number of oxygen

267 atoms added to the parent nitrocatechol molecule (ie. $+\mathrm{O},+2 \mathrm{O},+3 \mathrm{O}$, etc.). The formation of

268 these products is consistent with the addition of an $\mathrm{OH}$ group and loss of a $\mathrm{H}$ atom, commonly

269 observed with $\mathrm{OH}$ oxidation of an aromatic molecule. ${ }^{48-50}$ Proposed structures for the

270 functionalized products are shown in Figure 5. In Figure 4, the absorbance of the reaction

271 solution at $420 \mathrm{~nm}$ (reproduced from Figure 2) is overlaid on the time series of the

272 functionalization products to show the coincident time profiles. These profiles strongly suggest

273 that the oxidation products containing additional hydroxyl groups are increasing or maintaining

274 the absorption at this wavelength as nitrocatechol is being depleted. Hydroxyl groups donate

275 electron density to an aromatic ring, which can shift the absorbance of the molecule further into

276 the visible range of the spectrum. An example of this is shown in Figure S11 for the molecules

277 nitrobenzene and nitrophenol. The products corresponding to the $+\mathrm{O}$ to $+3 \mathrm{O}$ are consistent with

278 this mechanism.

279 It is also possible to have a structure, consistent with the observed molecular formulae for the

$280+2 \mathrm{O}$ to $+5 \mathrm{O}$ products, where the aromatic ring has opened by attack of a hydroxyl radical at an

281 already substituted position. A proposed ring-opening mechanism is shown in Figure S12. This

282 leads to a conjugated molecule with two carboxylic acid functional groups where the carbon-

283 carbon bond is broken (see Figure 5). The ring-opened products, which cannot be differentiated 
284 from the ring-closed structures of the same molecular formula, may also be forming during the

285 photo-oxidation and must be invoked to explain the $+4 \mathrm{O}$ and $+5 \mathrm{O}$ products, since the ring is

286 fully substituted after 3 functionalization steps. As these structures maintain extended

287 conjugation, they may still contribute to the absorption at $420 \mathrm{~nm}$, although their contribution is

288 uncertain. Similar functionalized products were observed to form up to $+4 \mathrm{O}$ and $+3 \mathrm{O}$ for

289 nitroguaiacol (Figure S7) and dinitrophenol (Figure S9), respectively.

290 Figure 6 shows the formation of a six-carbon oxidation product $\left(\mathrm{C}_{6} \mathrm{H}_{4} \mathrm{O}_{4}\right)$ with a similar time

291 profile to the $+\mathrm{O}$ compounds. However, the nitro-group has been lost from this molecule. The

292 molecular formula of this product is consistent with a dihydroxyquinone. Attack of the hydroxyl

293 radical at the position of the nitro-group could result in the release of the $\mathrm{NO}_{2}$ radical (which can

294 be oxidized to nitrate) and formation of a hydroquinone, which could subsequently be oxidized

295 to the quinone. A proposed mechanism for the loss of the nitro-group is shown in Figure S13.

296 Quinones have also been observed to form from the $\mathrm{OH}$ oxidation of nitrobenzene. ${ }^{48}$ The

297 quinone absorption spectrum extends into the visible region, such that these types of products

298 may also contribute to the observed absorption during the photo-oxidation reaction. 


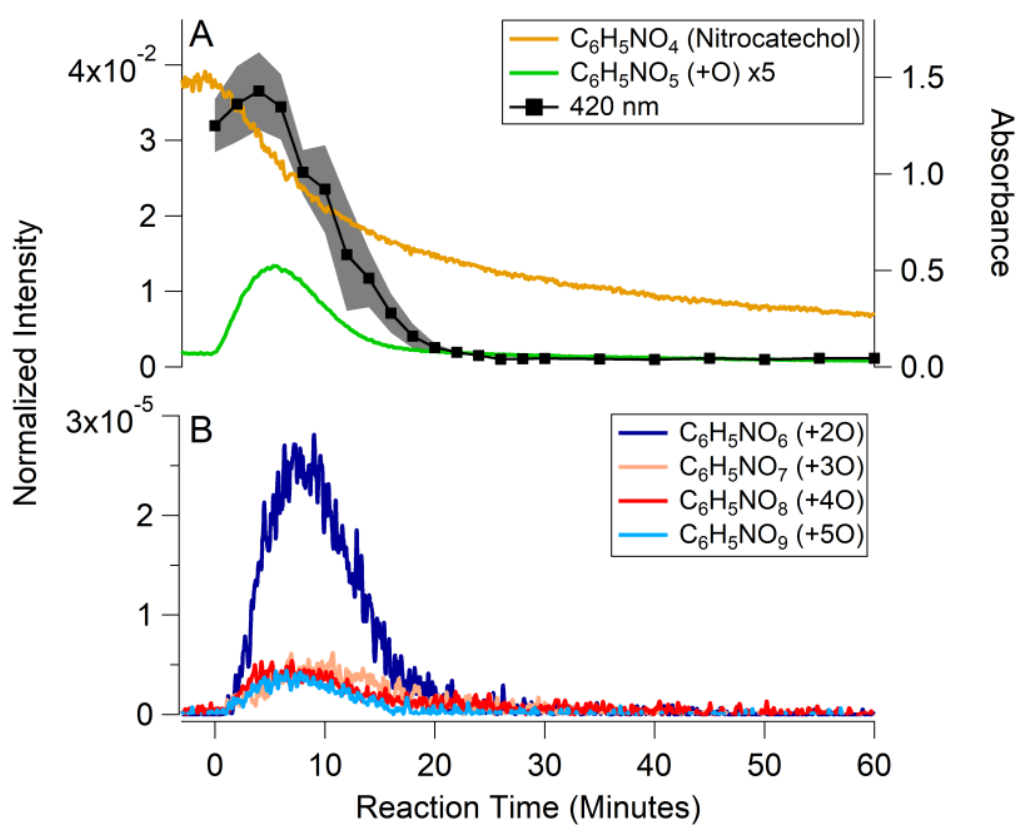

300 Figure 4. Decay of nitrocatechol and formation of functionalization products ( $+\mathrm{O}$ products) as a 301 function of reaction time from the photo-oxidation of nitrocatechol. The signal from each

302 molecule is normalized to the acetate reagent ion and the normalized intensity is plotted for 303 nitrocatechol and the $+\mathrm{O}$ product in panel $\mathrm{A}$ (left axis), and for the $+2 \mathrm{O}$ to $+5 \mathrm{O}$ products in panel 304 B. The $+\mathrm{O}$ product intensity has been multiplied by a factor of 5 , as indicated in the legend. The 305 absorption at $420 \mathrm{~nm}$ is reproduced from Figure 2 and overlaid in panel A (right axis) to 306 facilitate comparison with the formation of reaction products.

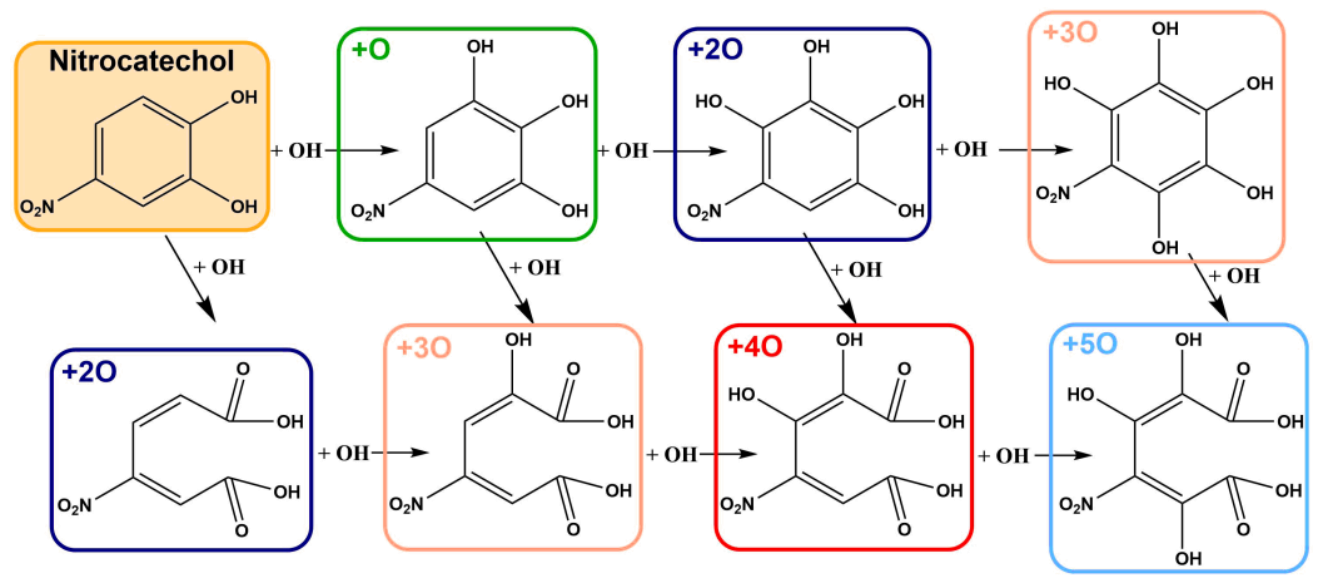

308 Figure 5. Proposed structures for the $\mathrm{OH}$ functionalization products of nitrocatechol photo-

309 oxidation shown in Figure 4 (using the same color scheme). Products with $+2 \mathrm{O}$ (dark blue) and $310+3 \mathrm{O}$ (peach) have two possible structures based on the molecular formula. 


\section{Fragmentation}

312 Figure 6 shows a selection of the observed fragmentation products from the photo-oxidation of

313 nitrocatechol. These products correspond to carbon numbers less than that of the parent molecule

314 (i.e., $\left.\mathrm{C}_{1}-\mathrm{C}_{5}\right)$ and they have been roughly divided into time profiles which peak early $(6-22$

315 minutes, Figure 6 panel A) and later (22 - 60 minutes, Figure 6 panel B) in the reaction.

316 Possible structures for these products are shown in Figure 7. Generally, molecules with carbon

317 numbers of $\mathrm{C}_{5}, \mathrm{C}_{4}$, and $\mathrm{C}_{3}$ formed earlier in the reaction, followed by molecules with fewer

318 carbons $\left(\mathrm{C}_{2}, \mathrm{C}_{1}\right)$. One notable exception to this is the early formation of glyoxylic acid $\left(\mathrm{C}_{2} \mathrm{H}_{2} \mathrm{O}_{3}\right)$.

319 This indicates that as the six-carbon molecules are broken down early in the reaction, glyoxylic

320 acid is produced along with the $\mathrm{C}_{3}-\mathrm{C}_{5}$ compounds. Other breakdown products with and without

321 nitrogen are observed to form early in the reaction, such as furoic acid $\left(\mathrm{C}_{5} \mathrm{H}_{4} \mathrm{O}_{3}\right)$, maleic acid

$322\left(\mathrm{C}_{4} \mathrm{H}_{4} \mathrm{O}_{4}\right)$, and nitroacrylic acid $\left(\mathrm{C}_{3} \mathrm{H}_{3} \mathrm{NO}_{4}\right)$ (see Figure 6). The identified fragmentation products

323 are not expected to absorb strongly in the near-UV and visible range, in agreement with the

324 observed loss of absorption at later reaction time ( $>10$ minutes).

325 Many compounds that peak later in the reaction persist longer, some maintaining appreciable

326 signal until the end of the experiment. Some of these compounds are common oxidation products

327 such as glycolic acid $\left(\mathrm{C}_{2} \mathrm{H}_{4} \mathrm{O}_{3}\right)$, malonic acid $\left(\mathrm{C}_{3} \mathrm{H}_{4} \mathrm{O}_{4}\right)$, and oxalic acid $\left(\mathrm{C}_{2} \mathrm{H}_{2} \mathrm{O}_{4}\right)$ (see Figure 6).

328 These small acids generally have slower reaction rates with $\mathrm{OH}$ radicals ${ }^{54}$ and may persist in the

329 aqueous phase. Loss of the nitro-group throughout the photo-oxidation was also observed, as

330 indicated by the formation of nitrous acid $\left(\mathrm{HNO}_{2}\right)$ and nitric acid $\left(\mathrm{HNO}_{3}\right)$ (not shown). This has

331 been observed previously in the $\mathrm{OH}$ oxidation of nitrobenzene where the nitro-group was lost

332 from the parent molecule and phenol and benzenediols were formed. ${ }^{48}$ In the case of

333 nitrocatechol, benzenediols or benzenetriols were not observed to form. The peak production of 
$334 \mathrm{HNO}_{2}$ and $\mathrm{HNO}_{3}$ occurs after 13 minutes and continues toward the end of the reaction time (see

335 Table S4), which suggests that the nitro-group is lost after significant oxidation of nitrocatechol,

336 from a ring-opened product or later in the reaction from a smaller fragment molecule. This

337 mechanism is further supported by the observation of lower carbon number products which

338 contain nitrogen in their molecular formulae, such as nitroacrylic acid $\left(\mathrm{C}_{3} \mathrm{H}_{3} \mathrm{NO}_{4}\right)$ and

339 nitropropanoic acid $\left(\mathrm{C}_{3} \mathrm{H}_{5} \mathrm{NO}_{4}\right)$ (see Table S4). Similar fragmentation products to nitrocatechol

340 were observed to form during photo-oxidation of nitroguaiacol (Figure S8) and dinitrophenol

341 (Figure S10) with a similar pattern of larger carbon number products appearing first, followed

342 by products with fewer carbons.

343 Surprisingly, isocyanic acid (HNCO) was also observed to form as a breakdown product during

344 the photo-oxidation of nitrocatechol (Figure 6, panel B). Previously, HNCO has been detected as

345 a gas phase photo-oxidation product of amines, ${ }^{55,56}$ a class of molecules in which nitrogen is

346 present in a reduced state (oxidation state of -3). This is the first observation of HNCO produced

347 during aqueous phase photo-oxidation from any source, as well as the first observation of HNCO

348 formation from a nitro-group where the nitrogen is in an oxidized state (oxidation state of +3 ).

349 HNCO formation was observed from photo-oxidation of all three nitrophenol molecules,

350 confirming that it is a common breakdown product for this class of molecules. The exact

351 mechanism leading to the formation of HNCO remains unclear and could not be determined

352 within the scope of this study, especially because it appears that the nitrogen atom is being

353 photo-reduced. We cannot rule out that some signal measured as HNCO may come from ion

354 fragmentation or thermal decomposition within the aerosol-CIMS setup. However, external

355 calibration confirmed that dissolved HNCO could be measured directly and quantified with the

356 aerosol-CIMS (Figure S14). Based on this calibration, the measured yield of HNCO from 
357 nitrocatechol photo-oxidation at the end of the reaction was approximately $9 \%$. There is some

358 indication towards the end of the reaction that $\mathrm{HNCO}$ concentrations are decreasing, which may

359 be due to hydrolysis. However, the observed decay cannot be fully accounted for by the

360 hydrolysis rate (assuming a $\mathrm{pH}$ between $6-7),{ }^{57}$ which may suggest photo-oxidation of HNCO,

361 although the latter was not confirmed. The aqueous photo-oxidation of nitrophenols may

362 contribute to the production of $\mathrm{HNCO}$ in cloud and aerosol liquid water, which can partition to

363 the gas phase according to its Henry's law constant. ${ }^{57}$ A photochemical source of $\mathrm{HNCO}$ was

364 observed to dominate at a field site in La Jolla, California, ${ }^{58}$ suggesting a significant unknown

365 daytime source for HNCO. Much remains to be discovered about the aqueous sources and sinks

366 of HNCO.

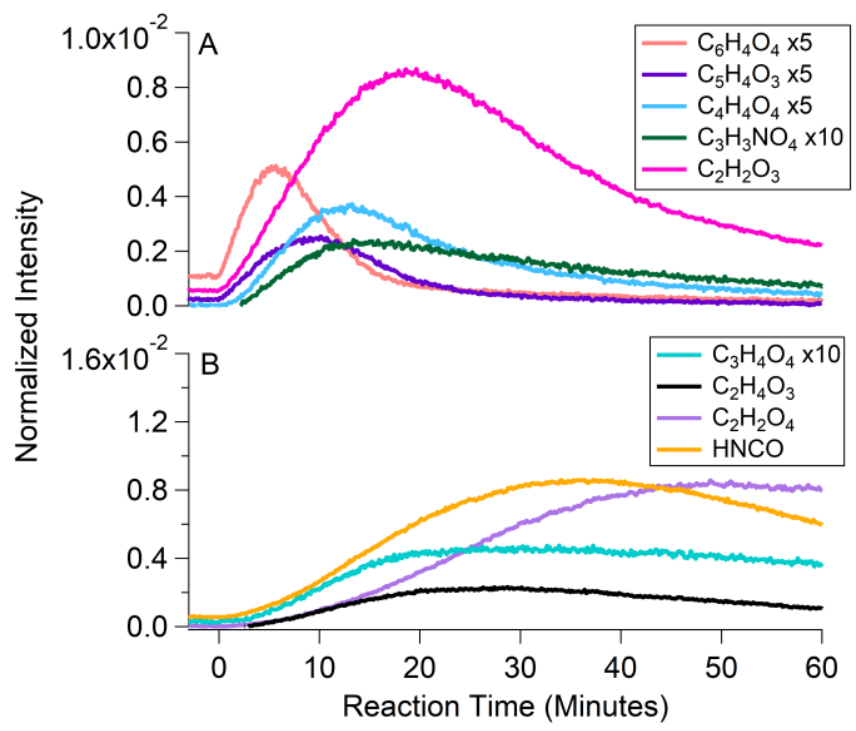

368 Figure 6. Formation of fragmentation products as a function of reaction time from the photo369 oxidation of nitrocatechol. The signal from each molecule is normalized to the acetate reagent 370 ion to give the normalized intensity. Panel A shows "early" fragmentation products and panel B 
371 shows "later" fragmentation products as discussed in text. Some product intensities have been 372 multiplied by a factor of 5 or 10 to be on scale with other molecules, as indicated in the legend.
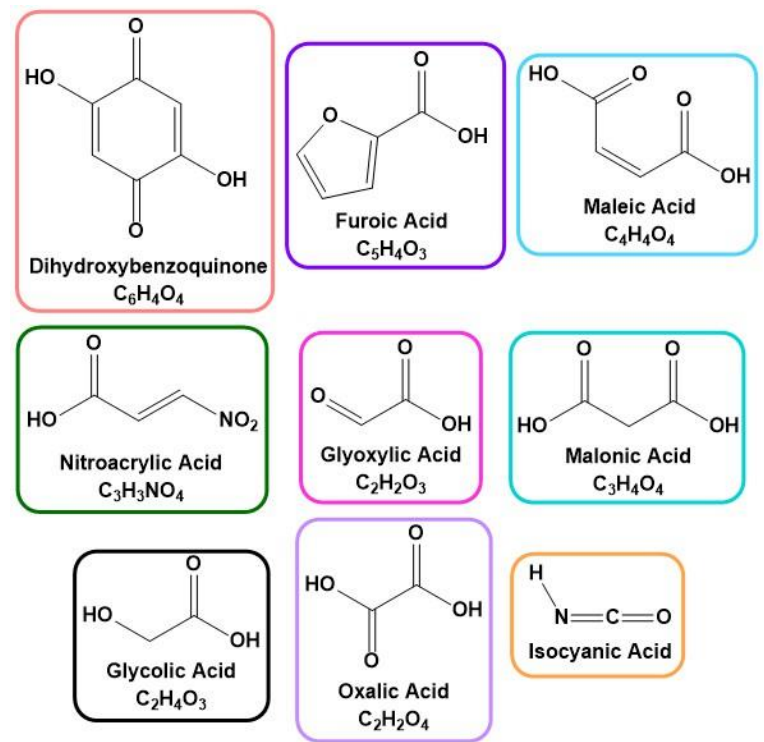

374 Figure 7. Proposed structures for fragmentation products formed from the photo-oxidation of 375 nitrocatechol (time profiles shown in Figure 6, using the same color scheme). CONCLUSIONS AND ENVIRONMENTAL IMPLICATIONS

377 Nitrophenols, specifically nitrocatechol, nitroguaiacol, and dinitrophenol, were observed to react

378 rapidly in the aqueous phase with hydroxyl radicals. The second order rate constants were

379 measured for each molecule and correspond to aqueous phase lifetimes on the order of hours,

380 assuming an $\mathrm{OH}$ radical concentration of $1 \times 10^{-14} \mathrm{M}$. Under cloud conditions, the rate of aqueous

381 phase $\mathrm{OH}$ oxidation dominates over the rate of gas phase oxidation, making the aqueous phase

382 an important reactive sink. This fast aqueous phase oxidation is consistent with measurements of

383 biomass burning $\mathrm{BrC}$ where nitrophenols are observed close to the source, but are less

384 concentrated or not found in aged samples further downwind of the source. ${ }^{23}$ While we have

385 examined aqueous phase oxidation under cloud water conditions, it is entirely likely that similar

386 processes occur by heterogeneous oxidation. 
387 The reaction products formed throughout the photo-oxidation of the nitrophenols were measured

388 online with the aerosol-CIMS and the corresponding evolution of the UV-Vis absorbance

389 spectrum was measured offline. Initially, the formation of functionalized products corresponding

390 to the addition of $\mathrm{OH}$ to the parent molecule was observed. The formation of these products

391 corresponded to the increased absorption in the visible range observed early in the reaction, even

392 after the light-absorbing parent molecule had been significantly depleted. Later in the reaction,

393 fragmentation products with smaller carbon numbers were observed, with signals arising from

394 small compounds like oxalic, glycolic, and malonic acids present at sustained levels until the end

395 of the observations. The loss of aromatic molecules through fragmentation to smaller molecules

396 parallels the loss in absorption intensity in the visible range. Isocyanic acid (HNCO) was also

397 observed to form during photo-oxidation of all three nitrophenols, indicating that this reaction

398 could be a secondary photochemical source of HNCO in the aqueous phase. The majority of

$399 \mathrm{HNCO}$ is thought to arise from primary emissions, although a secondary source was suggested

400 from field observations. ${ }^{58}$ Understanding the sources of $\mathrm{HNCO}$ is important because it is toxic

401 and can react with proteins in the body through carbamylation, with a potential impact on human

402 health. ${ }^{59,60}$

403 Although nitrophenols are observed to contribute to the light absorption in $\mathrm{BrC}$ aerosol from

404 biomass burning, they are reactive towards oxidation, especially in the aqueous phase. Early

405 steps in the reaction which functionalize the nitrophenol molecule can increase the absorption

406 intensity, possibly increasing the atmospheric warming potential of the $\mathrm{BrC}$. However, further

407 oxidation results in the formation of smaller organic acids which no longer contribute to

408 absorption in the visible wavelengths, thus photo-bleaching the $\mathrm{BrC}$. The overall warming

409 impact of the $\mathrm{BrC}$ will strongly depend on the amount of time nitrophenols spend in the 
410 atmospheric aqueous phase and the extent of oxidation by $\mathrm{OH}$ radicals. Since nitrophenols are

411 reactive towards oxidation as well as vulnerable to photolysis, ${ }^{18,26,27,61}$ they may not contribute to

412 long-lived $\mathrm{BrC}$ or significant atmospheric warming via the direct or semi-direct effects. If short-

413 lived species, such as nitrophenols, are not present at long photochemical times then it is possible

414 that the chemical composition of the long-lived BrC present in aged aerosol consists of less

415 chemically reactive oligomeric species with large molecular weights. ${ }^{62}$ We are currently

416 extending the methods used in this paper to study the chemical reactivity of such species.

\section{ASSOCIATED CONTENT}

\section{Supporting Information}

419 Supporting Information Available: Additional text and figures including aerosol-CIMS set-up and 420 voltage parameters, absorption of nitrophenols at $5 \mu \mathrm{M}$ and calculation of the total solar power 421 flux absorbed per solution, relative rate kinetics figures for all nitrophenols, $\mathrm{OH}$ concentration 422 calculation, gas phase nitrophenol rate constants and Henry's law constants, comparison of 423 aqueous and gaseous $\mathrm{OH}$ oxidation rates of nitrophenols, all identified products from photo424 oxidation of nitrophenols, control experiment for direct photolysis of nitrophenols, photo425 oxidation products for nitroguaiacol and dinitrophenol, UV-Visible spectrum of nitrobenzene and 426 nitrophenol, mechanisms for $\mathrm{OH}$-initiated ring opening and nitro-group loss, and aerosol-CIMS 427 calibration for HNCO.

\section{AUTHOR INFORMATION}

\section{Corresponding Author}

430 *E-mail: rachel.hems@mail.utoronto.ca, Telephone: 1-416-946-7359

\section{Author Contributions}

432 The manuscript was written with contributions from all authors. All authors have given approval 433 to the final version of the manuscript. 


\section{Funding Sources}

435 This work was supported by the Natural Sciences and Engineering Research Council of Canada 436 (NSERC).

\section{REFERENCES}

438 (1) Zhang, Y.; Forrister, H.; Liu, J.; Dibb, J.; Anderson, B.; Schwarz, J. P.; Perring, A. E.;

(2) Ramanathan, V.; Carmichael, G. Global and Regional Climate Changes due to Black Carbon. Nat. Geosci. 2008, 1, 221-227.

(3) Saleh, R.; Marks, M.; Heo, J.; Adams, P. J.; Donahue, N. M.; Robinson, A. L. Contribution

(4) Jo, D. S.; Park, R. J.; Lee, S.; Kim, S. W.; Zhang, X. A Global Simulation of Brown Carbon: of Brown Carbon and Lensing to the Direct Radiative Effect of Carbonaceous Aerosols from Biomass and Biofuel Burning Emissions. J. Geophys. Res. Atmos. 2015, 120 (10), $285-296$.

(5) Arola, A.; Schuster, G. L.; Pitkänen, M. R. A.; Dubovik, O.; Kokkola, H.; Lindfors, A. V.;

Mielonen, T.; Raatikainen, T.; Romakkaniemi, S.; Tripathi, S. N.; et al. Direct Radiative $12731-12740$.

(6) Feng, Y.; Ramanathan, V.; Kotamarthi, V. R. Brown Carbon: A Significant Atmospheric 
Absorber of Solar Radiation. Atmos. Chem. Phys. 2013, 13, 8607-8621.

456

457

458

459

460

461

462

463

464

465

466

467

468

469

470

471

472

473

474
(7) Laskin, A.; Laskin, J.; Nizkorodov, S. A. Chemistry of Atmospheric Brown Carbon. Chem. Rev. 2015, 115 (10), 4335-4382.

(8) Shapiro, E. L.; Szprengiel, J.; Sareen, N.; Jen, C. N.; Giordano, M. R.; McNeill, V. F. LightAbsorbing Secondary Organic Material Formed by Glyoxal in Aqueous Aerosol Mimics. Atmos. Chem. Phys. 2009, 9, 2289-2300.

(9) Lee, A. K. Y.; Zhao, R.; Li, R.; Liggio, J.; Li, S. M.; Abbatt, J. P. D. Formation of Light Absorbing Organo-Nitrogen Species from Evaporation of Droplets Containing Glyoxal and Ammonium Sulfate. Environ. Sci. Technol. 2013, 47 (22), 12819-12826.

(10) Bones, D. L.; Henricksen, D. K.; Mang, S. A.; Gonsior, M.; Bateman, A. P.; Nguyen, T. B.; Cooper, W. J.; Nizkorodov, S. A. Appearance of Strong Absorbers and Fluorophores in Limonene- $\mathrm{O}_{3}$ Secondary Organic Aerosol due to $\mathrm{NH}_{4}{ }^{+}$-Mediated Chemical Aging over Long Time Scales. J. Geophys. Res. Atmos. 2010, 115, D05203.

(11) Chang, J. L.; Thompson, J. E. Characterization of Colored Products Formed during Irradiation of Aqueous Solutions Containing $\mathrm{H}_{2} \mathrm{O}_{2}$ and Phenolic Compounds. Atmos. Environ. 2010, 44 (4), 541-551.

(12) Gelencser, A.; Hoffer, A.; Kiss, G.; Tombacz, E.; Kurdi, R.; Bencze, L. In-Situ Formation of Light-Absorbing Organic Matter in Cloud Water. J. Atmos. Chem. 2003, 45 (1), 25-33.

(13) Harrison, M. A. J.; Barra, S.; Borghesi, D.; Vione, D.; Arsene, C.; Iulian Olariu, R. Nitrated Phenols in the Atmosphere: A Review. Atmos. Environ. 2005, 39 (2), 231-248. 
475

476

477

478

479

480

481

482

483

484

485

486

487

488

489

490

491

492

493

494

495

(14) Mohr, C.; Lopez-Hilfiker, F. D.; Zotter, P.; Prevot, A. S. H.; Xu, L.; Ng, N. L.; Herndon, S. C.; Williams, L. R.; Franklin, J. P.; Zahniser, M. S.; et al. Contribution of Nitrated Phenols to Wood Burning Brown Carbon Light Absorption in Detling, United Kingdom during Winter Time. Environ. Sci. Technol. 2013, 47 (12), 6316-6324.

(15) Grosjean, D. Atmospheric Fate of Toxic Aromatic Compounds. Sci. Total Environ. 1991, $100,367-414$.

(16) Lin, P.; Liu, J.; Shilling, J. E.; Kathmann, S. M.; Laskin, J.; Laskin, A. Molecular Characterization of Brown Carbon (BrC) Chromophores in Secondary Organic Aerosol Generated from Photo-Oxidation of Toluene. Phys. Chem. Chem. Phys. 2015, 17, 2331223325.

(17) Forrister, H.; Liu, J.; Scheuer, E.; Dibb, J.; Ziemba, L.; Thornhill, K. L.; Anderson, B.; Diskin, G.; Perring, A. E.; Schwarz, J. P.; et al. Evolution of Brown Carbon in Wildfire Plumes. Geophys. Res. Lett. 2015, 42, 4623-4630.

(18) Zhao, R.; Lee, A. K. Y.; Huang, L.; Li, X.; Yang, F.; Abbatt, J. P. D. Photochemical Processing of Aqueous Atmospheric Brown Carbon. Atmos. Chem. Phys. 2015, 15, 60876100.

(19) Lee, H. J.; Aiona, P. K.; Laskin, A.; Laskin, J.; Nizkorodov, S. A. Effect of Solar Radiation on the Optical Properties and Molecular Composition of Laboratory Proxies of Atmospheric Brown Carbon. Environ. Sci. Technol. 2014, 48 (17), 10217-10226.

(20) Sareen, N.; Moussa, S. G.; McNeill, V. F. Photochemical Aging of Light-Absorbing Secondary Organic Aerosol Material. J. Phys. Chem. A 2013, 117 (14), 2987-2996. 
(21) Zhong, M.; Jang, M. Dynamic Light Absorption of Biomass-Burning Organic Carbon Photochemically Aged under Natural Sunlight. Atmos. Chem. Phys. 2014, 14, 1517-1525.

(22) Wong, J. P. S.; Nenes, A.; Weber, R. J. Changes in Light Absorptivity of Molecular Weight Separated Brown Carbon Due to Photolytic Aging. Environ. Sci. Technol. 2017, 51 (15), $8414-8421$.

(23) Di Lorenzo, R. A.; Young, C. J. Size Separation Method for Absorption Characterization in Brown Carbon: Application to an Aged Biomass Burning Sample. Geophys. Res. Lett. 2015, $43,458-465$.

(24) Di Lorenzo, R. A.; Washenfelder, R. A.; Attwood, A. R.; Guo, H.; Xu, L.; Ng, N. L.; Weber, R. J.; Baumann, K.; Edgerton, E.; Young, C. J. Molecular-Size-Separated Brown Carbon Absorption for Biomass-Burning Aerosol at Multiple Field Sites. Environ. Sci. Technol. 2017, $51(6), 3128-3137$.

(25) Albinet, A.; Minero, C.; Vione, D. UVA Irradiation Induces Direct Phototransformation of 2,4-Dinitrophenol in Surface Water Samples. Chemosphere 2010, 80 (7), 759-763.

(26) Zhao, S.; Ma, H.; Wang, M.; Cao, C.; Xiong, J.; Xu, Y.; Yao, S. Study on the Mechanism of Photo-Degradation of P-Nitrophenol Exposed to $254 \mathrm{Nm}$ UV Light. J. Hazard. Mater. 2010, $180(1-3), 86-90$.

(27) Bejan, I.; Abd-el-Aal, Y.; Barnes, I.; Benter, T.; Bohn, B.; Wiesen, P.; Kleffmann, J. The Photolysis of Ortho-Nitrophenols: A New Gas Phase Source of HONO. Phys. Chem. Chem. Phys. 2006, 8 (17), 2028-2035. 
(28) Chen, B.; Yang, C.; Goh, N. K. Direct Photolysis of Nitroaromatic Compounds in Aqueous Solutions. J. Environ. Sci. 2005, 17 (4), 598-604.

(29) Vione, D.; Maurino, V.; Minero, C.; Duncianu, M.; Olariu, R. I.; Arsene, C.; Sarakha, M.; Mailhot, G. Assessing the Transformation Kinetics of 2- and 4-Nitrophenol in the Atmospheric Aqueous Phase. Implications for the Distribution of Both Nitroisomers in the Atmosphere. Atmos. Environ. 2009, 43 (14), 2321-2327.

(30) Slade, J. H.; Knopf, D. A. Heterogeneous OH Oxidation of Biomass Burning Organic Aerosol Surrogate Compounds: Assessment of Volatilisation Products and the Role of OH Concentration on the Reactive Uptake Kinetics. Phys. Chem. Chem. Phys. 2013, 15 (16), $5898-5915$.

(31) Slade, J. H.; Knopf, D. A. Multiphase OH Oxidation Kinetics of Organic Aerosol : The Role of Particle Phase State and Relative Humidity. Geophys. Res. Lett. 2014, 41, 5297-5306.

(32) Sumlin, B. J.; Pandey, A.; Walker, M. J.; Pattison, R. S.; Williams, B. J.; Chakrabarty, R. K. Atmospheric Photooxidation Diminishes Light Absorption by Primary Brown Carbon Aerosol from Biomass Burning. Environ. Sci. Technol. Lett. 2017, 4 (12), 540-545.

(33) Gilardoni, S.; Massoli, P.; Paglione, M.; Giulianelli, L.; Carbone, C.; Rinaldi, M.; Decesari, S.; Sandrini, S.; Costabile, F.; Gobbi, G. P.; et al. Direct Observation of Aqueous Secondary Organic Aerosol from Biomass-Burning Emissions. Proc. Natl. Acad. Sci. 2016, 113 (36), 10013-10018.

(34) Desyaterik, Y.; Sun, Y.; Shen, X.; Lee, T.; Wang, X.; Wang, T.; Collett, J. L. Speciation Of "brown” carbon in Cloud Water Impacted by Agricultural Biomass Burning in Eastern 
China. J. Geophys. Res. Atmos. 2013, 118 (13), 7389-7399.

538

(35) Hinrichs, R. Z.; Buczek, P.; Trivedi, J. J. Solar Absorption by Aerosol-Bound Nitrophenols Compared to Aqueous and Gaseous Nitrophenols. Environ. Sci. Technol. 2016, 50 (11), $5661-5667$.

(36) Aljawhary, D.; Lee, A. K. Y.; Abbatt, J. P. D. High-Resolution Chemical Ionization Mass Spectrometry (ToF-CIMS): Application to Study SOA Composition and Processing. Atmos. Meas. Tech. 2013, 6, 3211-3224.

(37) Aljawhary, D.; Zhao, R.; Lee, A. K. Y.; Wang, C.; Abbatt, J. P. D. Kinetics, Mechanism, and Secondary Organic Aerosol Yield of Aqueous Phase Photo-Oxidation of $\alpha$-Pinene Oxidation Products. J. Phys. Chem. A 2016, 120 (9), 1395-1407.

(38) Zhao, R.; Mungall, E. L.; Lee, A. K. Y.; Aljawhary, D.; Abbatt, J. P. D. Aqueous-Phase Photooxidation of Levoglucosan - A Mechanistic Study Using Aerosol Time-of-Flight Chemical Ionization Mass Spectrometry (Aerosol ToF-CIMS). Atmos. Chem. Phys. 2014, $14,9695-9705$.

(39) Zhao, R.; Aljawhary, D.; Lee, A. K. Y.; Abbatt, J. P. D. Rapid Aqueous-Phase Photooxidation of Dimers in the $\alpha$-Pinene Secondary Organic Aerosol. Environ. Sci. Technol. Lett. 2017, 4 (6), 205-210.

(40) Veres, P.; Roberts, J. M.; Warneke, C.; Welsh-Bon, D.; Zahniser, M.; Herndon, S.; Fall, R.; de Gouw, J. Development of Negative-Ion Proton-Transfer Chemical-Ionization Mass Spectrometry (NI-PT-CIMS) for the Measurement of Gas-Phase Organic Acids in the Atmosphere. Int. J. Mass Spectrom. 2008, 274 (1-3), 48-55. 
558

(41) Brophy, P.; Farmer, D. K. Clustering, Methodology, and Mechanistic Insights into Acetate Chemical Ionization Using High-Resolution Time-of-Flight Mass Spectrometry. Atmos. Meas. Tech. 2016, 9, 3969-3986.

(42) Herrmann, H.; Schaefer, T.; Tilgner, A.; Styler, S. A.; Weller, C.; Teich, M.; Otto, T. Tropospheric Aqueous-Phase Chemistry: Kinetics, Mechanisms, and Its Coupling to a Changing Gas Phase. Chem. Rev. 2015, 115 (10), 4259-4334.

(43) García Einschlag, F. S.; Carlos, L.; Capparelli, A. L. Competition Kinetics Using the $\mathrm{UV} / \mathrm{H}_{2} \mathrm{O}_{2}$ Process: A Structure Reactivity Correlation for the Rate Constants of Hydroxyl Radicals toward Nitroaromatic Compounds. Chemosphere 2003, 53 (1), 1-7.

(44) Onstein, P.; Stefan, M. I.; Bolton, J. R. Competition Kinetics Method for the Determination of Rate Constants for the Reaction of Hydroxyl Radicals with Organic Pollutants Using the $\mathrm{UV} / \mathrm{H}_{2} \mathrm{O}_{2}$ Advanced Oxidation Technology: The Rate Constants for the Tert-Butyl Formate Ester an. J. Adv. Oxid. Technol. 1999, 4 (2), 231-236.

(45) Arakaki, T.; Anastasio, C.; Kuroki, Y.; Nakajima, H.; Okada, K.; Kotani, Y.; Handa, D.; Azechi, S.; Kimura, T.; Tsuhako, A.; et al. A General Scavenging Rate Constant for Reaction of Hydroxyl Radical with Organic Carbon in Atmospheric Waters. Environ. Sci. Technol. 2013, 47 (15), 8196-8203.

(46) Herrmann, H.; Hoffmann, D.; Schaefer, T.; Tilgner, A. Tropospheric Aqueous-Phase FreeRadical Chemistry: Radical Sources, Spectra, Reaction Kinetics and Prediction Tools. ChemPhysChem 2010, 11 (18), 3796-3822.

(47) Ervens, B.; George, C.; Williams, J. E.; Buxton, G. V.; Salmon, G. A.; Bydder, M.; 
Wilkinson, F.; Dentener, F.; Mirabel, P.; Wolke, R.; et al. CAPRAM 2.4 (MODAC Mechanism): An Extended and Condensed Tropospheric Aqueous Phase Mechanism and Its Application. J. Geophys. Res. 2003, 108 (D14), 4426.

(48) Zhao, L.; Ma, J.; Sun, Z. Oxidation Products and Pathway of Ceramic HoneycombCatalyzed Ozonation for the Degradation of Nitrobenzene in Aqueous Solution. Appl. Catal. B Environ. 2008, 79 (3), 244-253.

(49) Sun, Y. L.; Zhang, Q.; Anastasio, C.; Sun, J. Insights into Secondary Organic Aerosol Formed via Aqueous-Phase Reactions of Phenolic Compounds Based on High Resolution Mass Spectrometry. Atmos. Chem. Phys. 2010, 10, 4809-4822.

(50) Bing, C.; Chun, Y.; Khang, G. O. H. N. Photolysis Pathway of Nitroaromatic Compounds in Aqueous Solutions in the $\mathrm{UV} / \mathrm{H}_{2} \mathrm{O}_{2}$ Process. J. Environ. Sci. 2006, 18 (6), 1061-1064.

(51) Carlton, A. G.; Turpin, B. J.; Altieri, K. E.; Seitzinger, S.; Reff, A.; Lim, H. J.; Ervens, B. Atmospheric Oxalic Acid and SOA Production from Glyoxal: Results of Aqueous Photooxidation Experiments. Atmos. Environ. 2007, 41 (35), 7588-7602.

(52) Tan, Y.; Perri, M. J.; Seitzinger, S. P.; Turpin, B. J. Effects of Precursor Concentration and Acidic Sulfate in Aqueous Glyoxal - OH Radical Oxidation and Implications for Secondary Organic Aerosol. Environ. Sci. Technol. 2009, 43 (21), 8105-8112.

(53) Yu, L.; Smith, J.; Laskin, A.; Anastasio, C.; Laskin, J.; Zhang, Q. Chemical Characterization of SOA Formed from Aqueous-Phase Reactions of Phenols with the Triplet Excited State of Carbonyl and Hydroxyl Radical. Atmos. Chem. Phys. 2014, 14 (24), 13801-13816. 
(54) Herrmann, H. Kinetics of Aqueous Phase Reactions Relevant for Atmospheric Chemistry. Chem. Rev. 2003, 103 (12), 4691-4716.

(55) Borduas, N.; Abbatt, J. P. D.; Murphy, J. G. Gas Phase Oxidation of Monoethanolamine (MEA) with OH Radical and Ozone: Kinetics, Products, and Particles. Environ. Sci. Technol. 2013, 47 (12), 6377-6383.

(56) Borduas, N.; Da Silva, G.; Murphy, J. G.; Abbatt, J. P. D. Experimental and Theoretical Understanding of the Gas Phase Oxidation of Atmospheric Amides with OH Radicals: Kinetics, Products, and Mechanisms. J. Phys. Chem. A 2015, 119 (19), 4298-4308.

(57) Borduas, N.; Place, B.; Wentworth, G. R.; Abbatt, J. P. D.; Murphy, J. G. Solubility and Reactivity of HNCO in Water: Insights into HNCO's Fate in the Atmosphere. Atmos. Chem. Phys. 2016, 16, 703-714.

(58) Zhao, R.; Lee, A. K. Y.; Wentzell, J. J. B.; McDonald, A. M.; Toom-Sauntry, D.; Leaitch, W. R.; Modini, R. L.; Corrigan, A. L.; Russell, L. M.; Noone, K. J.; et al. Cloud Partitioning of Isocyanic Acid (HNCO) and Evidence of Secondary Source of HNCO in Ambient Air. Geophys. Res. Lett. 2014, 41 (19), 6962-6969.

(59) Wang, Z.; Nicholls, S. J.; Rodriguez, E. R.; Kummu, O.; Hörkkö, S.; Barnard, J.; Reynolds, W. F.; Topol, E. J.; DiDonato, J. A.; Hazen, S. L. Protein Carbamylation Links Inflammation, Smoking, Uremia and Atherogenesis. Nat. Med. 2007, 13 (10), 1176-1184.

(60) Roberts, J. M.; Veres, P. R.; Cochran, A. K.; Warneke, C.; Burling, I. R.; Yokelson, R. J.; Lerner, B.; Gilman, J. B.; Kuster, W. C.; Fall, R.; et al. Isocyanic Acid in the Atmosphere and Its Possible Link to Smoke-Related Health Effects. Proc. Natl. Acad. Sci. 2011, 108 
621 (61) Barsotti, F.; Bartels-Rausch, T.; De Laurentiis, E.; Ammann, M.; Brigante, M.; Mailhot, G.; Maurino, V.; Minero, C.; Vione, D. Photochemical Formation of Nitrite and Nitrous Acid (HONO) upon Irradiation of Nitrophenols in Aqueous Solution and in Viscous Secondary

(62) Saleh, R.; Robinson, E. S.; Tkacik, D. S.; Ahern, A. T.; Liu, S.; Aiken, A. C.; Sullivan, R. C.; Presto, A. A.; Dubey, M. K.; Yokelson, R. J.; et al. Brownness of Organics in Aerosols 650.

630 Table of Contents Graphic:

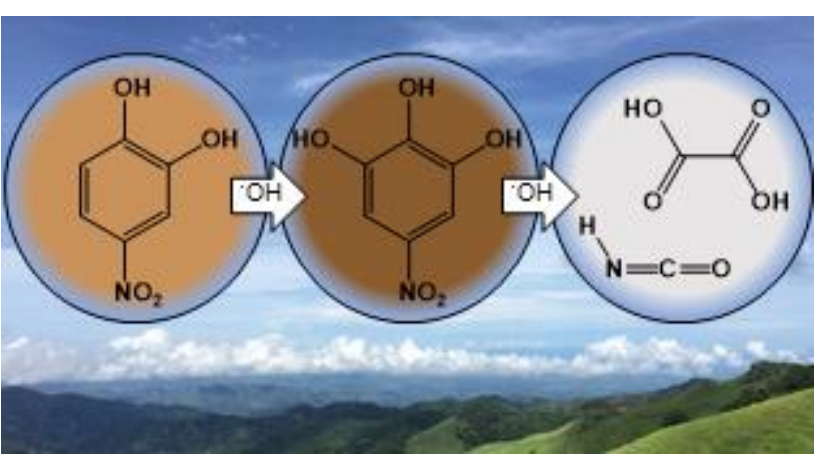




\section{Supporting Information for:}

2 Aqueous Phase Photo-oxidation of Brown Carbon

3 Nitrophenols: Reaction Kinetics, Mechanism, and

4 Evolution of Light Absorption

5 Rachel F. Hems ${ }^{1 *}$, Jonathan P. D. Abbatt ${ }^{1}$

6 * Corresponding Author: Email: rachel.hems@mail.utoronto.ca, Telephone: 1-416-946-7359

$7{ }^{1}$ Department of Chemistry, University of Toronto, 80 St. George Street, Toronto, ON, M5S 3H6,

8 Canada

9

10

11

12

13

14

15

16

17

18 


\section{Calculation of $\mathbf{O H}$ radical steady state concentration}

20 The steady state $\mathrm{OH}$ concentration $\left([\mathrm{OH}]_{\mathrm{ss}}\right)$ was calculated based on the pseudo-first order decay

21 of benzoic acid (BA), which has a known second order rate constant with $\mathrm{OH}$. The equation for

22 the pseudo-first order decay (1), the relationship between the pseudo-first order rate constant and

23 the second order rate constant (2), and the integrated first order decay (3) are shown below:

$$
-\frac{d[B A]}{d t}=k^{I}[B A]
$$

$$
k^{I}=k^{I I}[O H]_{S S}
$$

$$
\ln \left(\frac{[B A]_{t}}{[B A]_{0}}\right)=-k^{I} t
$$

27 A plot of the left side of equation 3 as a function of time gives the pseudo-first order rate

28 constant $\left(\mathrm{k}^{\mathrm{I}}\right)$. Using equation 2 , and the second order rate constant for benzoic acid $(5.9 \pm 0.5 \times$

$\left.2910^{9} \mathrm{M}^{-1} \mathrm{~s}^{-1}\right)^{1}$ the concentration of $\mathrm{OH}$ can be calculated. The $\mathrm{OH}$ steady state concentration was

30 determined to be $(3-4) \times 10^{-13} \mathrm{M}$.

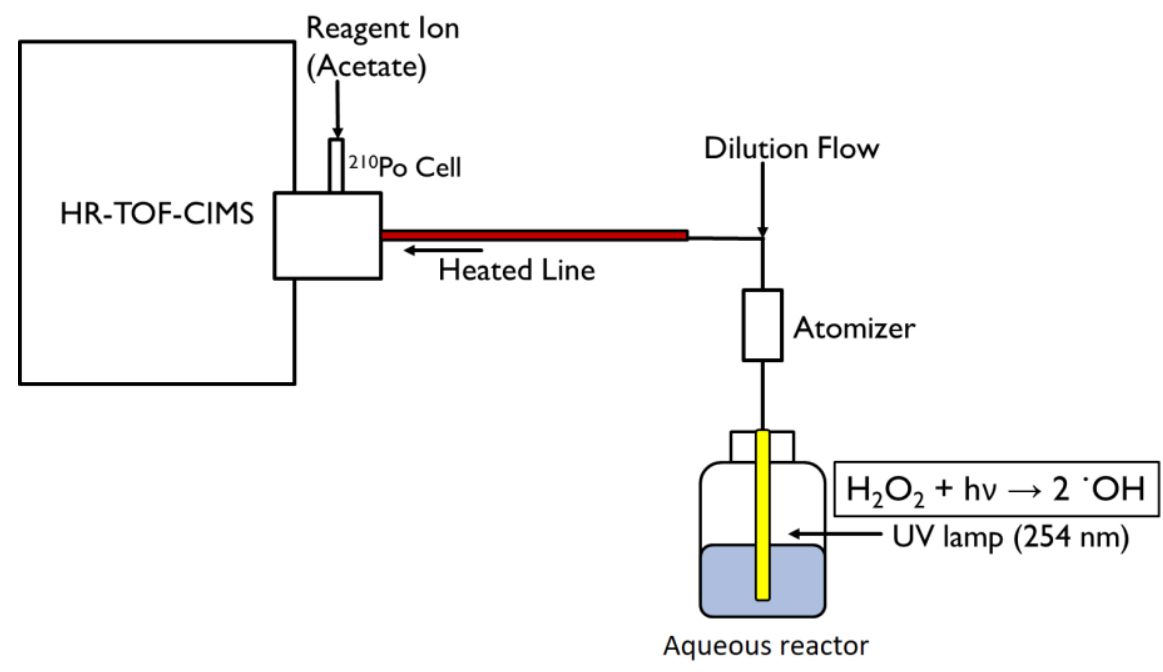

33 Figure S1. Experimental set-up of the aerosol-CIMS for online analysis of aqueous phase 34 oxidation of nitrophenol molecules. 
36 Table S1. CIMS voltage and RF parameters for strong-field mode.

\begin{tabular}{|l|l|l|l|}
\hline Component & Setting & Component & Setting \\
\hline IMR & $0 \mathrm{~V}$ & RF Ampl. 1 & 0.24 \\
\hline Nozzle & $3.333 \mathrm{~V}$ & RF 1 & $3090000 \mathrm{~Hz}$ \\
\hline Q1 Entr. Pl & $6.634 \mathrm{~V}$ & RF Ampl. 2 & 3.0 \\
\hline Q1 Front & $17.935 \mathrm{~V}$ & RF 2 & $4300000 \mathrm{~Hz}$ \\
\hline Q1 Back & $-8.056 \mathrm{~V}$ & U+ low & $700 \mathrm{~V}$ \\
\hline Lens Skimmer & $-7.233 \mathrm{~V}$ & U+ high & $35 \mathrm{~V}$ \\
\hline Skimmer & $-1.38 \mathrm{~V}$ & U- low & $50 \mathrm{~V}$ \\
\hline Q2 Front & $8.28 \mathrm{~V}$ & U- high & $680 \mathrm{~V}$ \\
\hline Q2 Back & $7.164 \mathrm{~V}$ & Lens & $1500 \mathrm{~V}$ \\
\hline Skimmer 2 & $11.403 \mathrm{~V}$ & Drift & $3000 \mathrm{~V}$ \\
\hline Reference & $48.383 \mathrm{~V}$ & Refl. Grid & $657 \mathrm{~V}$ \\
\hline Ion Lens & $97.89 \mathrm{~V}$ & Refl. Backplane & $700 \mathrm{~V}$ \\
\hline Defl. Flange & $38.85 \mathrm{~V}$ & Hardmirror & $0 \mathrm{~V}$ \\
\hline Deflector & $41.504 \mathrm{~V}$ & Post Acc. & $2700 \mathrm{~V}$ \\
\hline
\end{tabular}

38 Absorption of nitrophenols at a lower concentration ( $5 \mu \mathrm{M})$ and calculation of the product of nitrophenol absorption and solar power flux

40 The evolution of absorption for nitrocatechol, nitroguaiacol, and dinitrophenol was measured at a

41 lower concentration $(5 \mu \mathrm{M})$ than presented in the manuscript $(30 \mu \mathrm{M})$ to allow for accurate

42 measurement across the entire wavelength range. The measurement at $30 \mu \mathrm{M}$ optimized the

43 sensitivity of the absorption in the $400-500 \mathrm{~nm}$ range, however the absorbance below $400 \mathrm{~nm}$

44 was saturated and could not be accurately measured. The change in the absorbance spectra as a

45 function of reaction time is shown in Figure $\mathbf{S} 2$ for the three nitrophenols. 

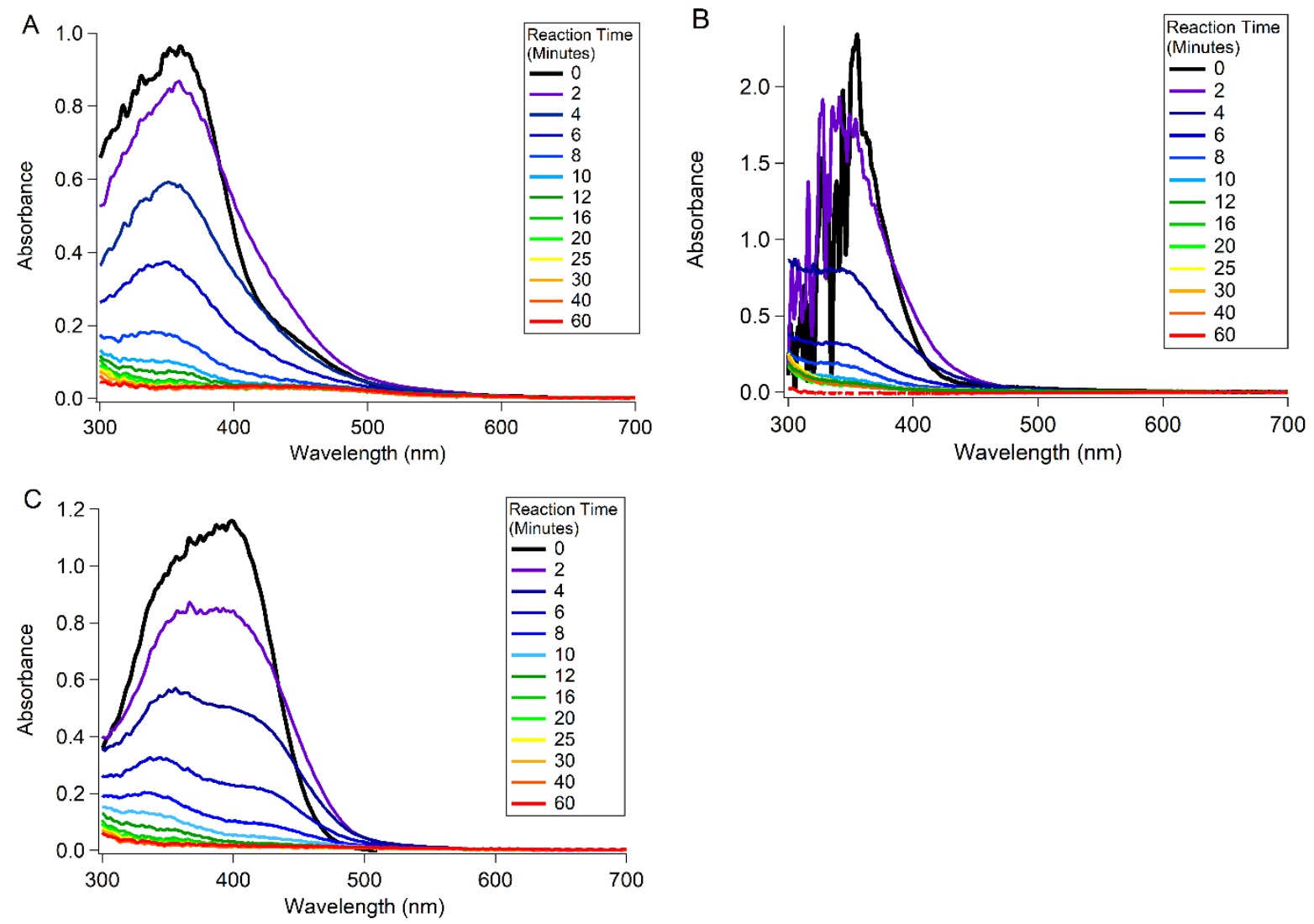

48 Figure S2. Absorption spectra of nitrocatechol (A), nitroguaiacol (B), and dinitrophenol (C) during photo-oxidation at a reduced concentration of $5 \mu \mathrm{M}$.

50 To examine the relative effect of the absorption change in the nitrophenols during the photo-

51 oxidation reaction on the amount of sunlight absorbed, the product of the specific nitrophenol

52 absorption in solution and typical solar power flux has been calculated and integrated across

53 wavelengths between $300-700 \mathrm{~nm}$ according to the following equation:

Total solar power flux absorbed per solution $=$

$$
\int_{300 \mathrm{~nm}}^{700 \mathrm{~nm}} \text { SolarPowerFlux }(\lambda) \times \text { Absorbance }(\lambda) d \lambda
$$

56 The solar power flux (irradiance, units of $\mathrm{W} \mathrm{m}^{-2} \mathrm{~nm}^{-1}$ ) was calculated as the total downwelling

57 radiation using the National Center for Atmospheric Research's “Quick TUV Calculator”,

58 available here: http://cprm.acom.ucar.edu/Models/TUV/Interactive_TUV/. The following

59 parameters were used: $\mathrm{SZA}=0^{\circ}$, overhead ozone column $=300$ Dobson units, surface albedo $=$

600.1 , and ground elevation $=0 \mathrm{~km}$. 
61 The product of the solar power flux and the absorbance for each nitrophenol molecule is

62 presented as a function of reaction time in Figure S3. The trend of increased intensity in the first

63 few minutes of the reaction is carried through in this parameter for nitrocatechol and

64 nitroguaiacol, indicating that the increased absorbance between $400-500 \mathrm{~nm}$ that the

65 nitrophenols exhibit during photo-oxidation can cause a significant increase in the relative

66 amount of sunlight absorbed by these compounds across the spectrum. While for dinitrophenol,

67 the increased absorbance between $400-500 \mathrm{~nm}$ during photo-oxidation slows the decline in the

68 relative amount of sunlight absorbed.

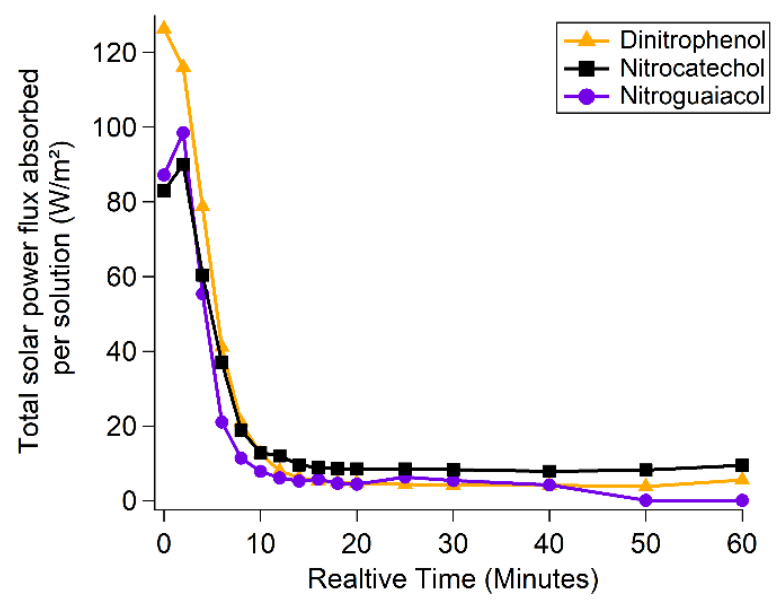

70 Figure S3. The product of molecular absorption and solar flux, integrated across wavelengths

$71300-700 \mathrm{~nm}$ as a function of $\mathrm{OH}$ reaction time for nitrocatechol, nitroguaiacol, and

72 dinitrophenol. 
80 Relative Rate Kinetics - Kinetic decay plots of nitrocatechol, nitroguaiacol, and 81 dinitrophenol with benzoic acid as the reference compound

82
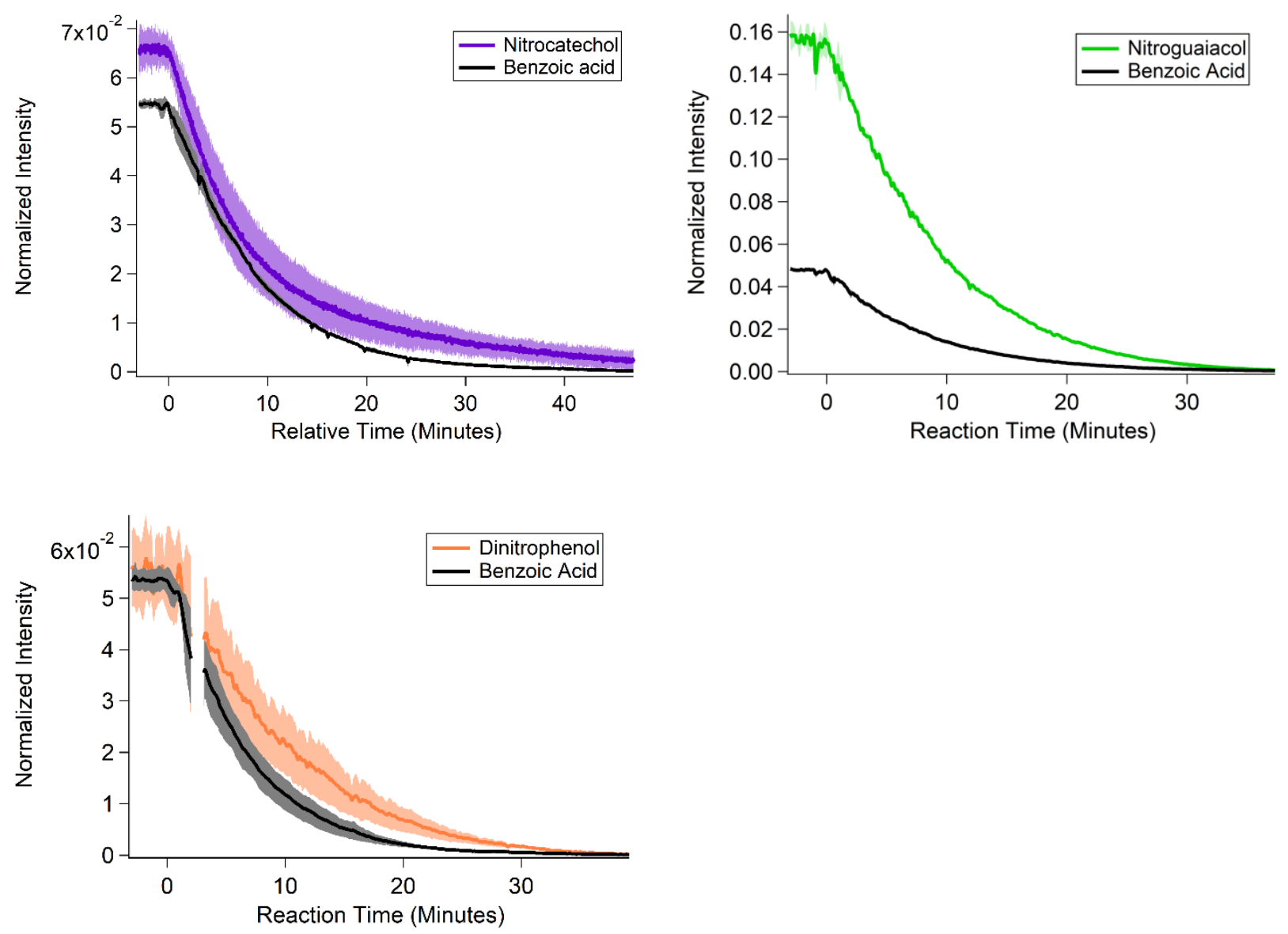

84 Figure S4. Nitrocatechol, nitroguaiacol, and dinitrophenol relative decay with OH reaction time,

85 with benzoic acid as the reference compound. The average of multiple $(\geq 2)$ experiments is

86 presented with one standard deviation shown as the shading.

87

88

89

90

91 

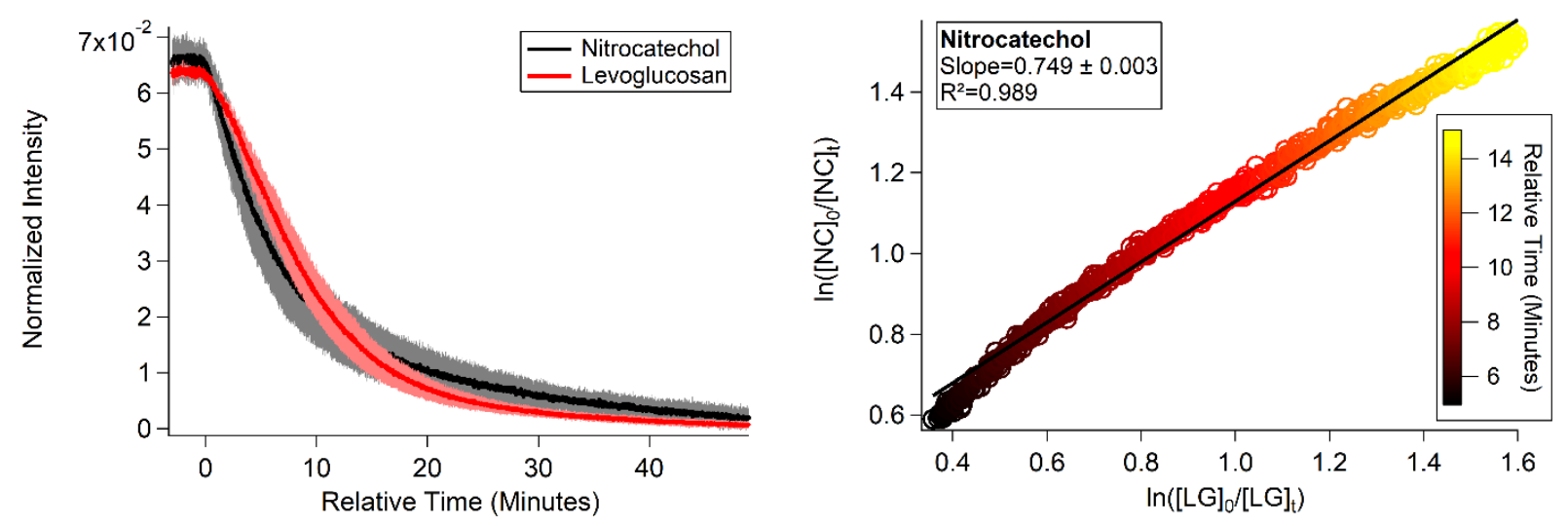

94 Figure S5. Nitrocatechol relative rate decay with levoglucosan as the reference compound (left).

95 The average of multiple $(\geq 2)$ experiments is presented with one standard deviation shown as the

96 shading. Relative rate kinetics plot of nitrocatechol and levoglucosan (right). Colour scale

97 corresponds to $\mathrm{OH}$ reaction time.

98 Levoglucosan was used as a reference compound for the measurement of the nitrocatechol second

99 order rate constant to confirm the measurements with benzoic acid as the reference compound.

100 The voltages in the CIMS were adjusted to favour complexation of the acetate reagent ion with the

101 analytes. Levoglucosan was detected as its cluster with acetate $(\mathrm{m} / z 221)$, while nitrocatechol was

102 still detected as the negative ion $(\mathrm{m} / \mathrm{z} 154)$. Due to the lower volatility of levoglucosan, the decay

103 was observed to be delayed, likely from desorption of levoglucosan from the heated line in the

104 aerosol-CIMS setup. This phenomenon of delayed levoglucosan decay was observed previously

105 with the same set-up in our laboratory. ${ }^{2}$ Due to this delay, the relative rate was calculated for data

106 from a relative time of 5-15 minutes, resulting in a relative rate kinetics plot (Figure S5, right) that

107 does not extend to 0,0 on the $\mathrm{x}$ - and $\mathrm{y}$-axes. The deviation from perfect $1^{\text {st }}$ order decay can explain

108 the non-linearity in the relative rate kinetics plot and introduces additional uncertainty to the

109 measurement.

110 The second order rate constant for nitrocatechol with $\mathrm{OH}$ radical, using levoglucosan as the 111 reference compound was calculated to be: $\mathrm{k}_{\mathrm{OH}}^{\mathrm{II}}=(4.4 \pm 0.4) \times 10^{9} \mathrm{M}^{-1} \mathrm{~s}^{-1}$. This value is similar to 112 the value for nitrocatechol measured with benzoic acid as the reference compound, although it is 113 not within the experimental error. Due to the challenges associated with this measurement, we 
114 suggest the rate constant should have a larger reported error to include the variability between the 115 two reference compounds. The second order rate constant for nitrocatechol with $\mathrm{OH}$ radical we 116 report is $5( \pm 1) \times 10^{9} \mathrm{M}^{-1} \mathrm{~s}^{-1}$, as discussed in the manuscript relative rate kinetics section.

\section{Comparison of the aqueous and gaseous $\mathrm{OH}$ oxidation rates of nitrophenols under cloudy} 118 conditions

119 To compare the relative importance of the $\mathrm{OH}$ oxidation of nitrocatechol, nitroguaiacol, and 120 dinitrophenol in the aqueous and gas phase, the ratio (W) of the rate of gas phase $\mathrm{OH}$ oxidation 121 and the rate of aqueous phase $\mathrm{OH}$ oxidation was calculated according to the analysis in Epstein 122 and Nizkorodov ${ }^{3}$, and shown in the equation below:

$$
W=\frac{\frac{d n_{X}^{g a s}}{d t}}{\frac{d n_{X}^{a q}}{d t}}=\left(L W C_{V} \times K_{H} \times R \times T\right)^{-1} \times\left(\frac{k_{X+O H}^{g a s}}{k_{X+O H}^{a q}}\right) \times\left(\frac{C_{O H}^{g a s}}{c_{O H}^{a q}}\right)
$$

124 Where $\mathrm{LWC}_{\mathrm{V}}$ is the volume based liquid water content, in units of volume of water per volume of 125 air. A representative value of $\mathrm{LWC}=0.5 \mathrm{~g} \mathrm{~m}^{-3}\left(\mathrm{LWC}=5 \times 10^{-4} \mathrm{~L} \mathrm{~m}^{-3}\right)$ was used based on previous measurements and the analysis in Epstein and Nizkorodov. ${ }^{3} \mathrm{~K}_{\mathrm{H}}$ is the Henry's law constant for the

127 nitrophenol species in units of $\mathrm{mol} \mathrm{atm}^{-1} \mathrm{~L}^{-1}$ (Table S2), $\mathrm{R}$ is the gas constant in units of $\mathrm{m}^{3} \mathrm{~atm}$ $128 \mathrm{~K}^{-1} \mathrm{~mol}^{-1}$, and T is temperature, which was set to $298 \mathrm{~K} . k_{X+O H}^{g a s}$ is the gas phase rate constant for 129 the reaction of the nitrophenol with $\mathrm{OH}$ (as predicted by EPISuite, listed in Table S2), $k_{X+O H}^{a q}$ is 130 the aqueous phase rate constant for the reaction of the nitrophenol with $\mathrm{OH}$, as measured in this 131 study. $C_{O H}^{g a s}$ is the gas phase $\mathrm{OH}$ concentration, which was set to be a value of $1 \times 10^{6} \mathrm{molec}^{-3}$, 132 and $C_{O H}^{a q}$ is the aqueous phase $\mathrm{OH}$ concentration, which was set to a value of $1 \times 10^{-14} \mathrm{M}$.

133 The calculated ratios (W) for each nitrophenol molecule are listed in Table S3. For all the 134 nitrophenol molecules, $\mathrm{W}$ is less than 1, indicating that the aqueous phase $\mathrm{OH}$ oxidation is 135 dominant over gas phase $\mathrm{OH}$ oxidation. These ratios seem to be largely driven by the Henry's law 136 constants for these molecules which indicate that they largely favor the aqueous phase. This simple 137 analysis does not take into account the variability in the LWC, or the aqueous and gas phase 138 concentrations of $\mathrm{OH}$. The sink by $\mathrm{OH}$ oxidation of the nitrophenols will depend on the amount of 139 liquid water, the $\mathrm{OH}$ concentrations, as well as the temporal variability of these two factors. This 
140 calculation does not consider any direct photolysis, which may also be a nitrophenol sink in the 141 gas and aqueous phases.

142 Table S2. Gas phase second order rate constants of nitrophenol compounds with $\mathrm{OH}$ radicals and 143 Henry's law constants, predicted from EPISuite, and calculated gas phase lifetime.

\begin{tabular}{|l|c|l|c|}
\hline Molecule & $\mathbf{k}^{\mathbf{I I}} \mathbf{O H}\left(\mathbf{c m}^{\mathbf{3}} \mathbf{~ m o l e c}^{-\mathbf{1}} \mathbf{s e c}^{-\mathbf{1}}\right)$ & $\begin{array}{l}\text { Lifetime (hours) } \\
\text { Assuming }[\mathrm{OH}]=1 \times 10^{6} \\
\text { molec/cm }\end{array}$ & $\begin{array}{l}\text { Henry's law constant, } \\
\mathbf{K}_{\mathbf{H}}\left(\mathbf{m o l ~ a t m}^{\mathbf{- 1}} \mathbf{L}^{-\mathbf{1}}\right)\end{array}$ \\
\hline 4-Nitrocatechol & $3.15 \times 10^{-12}$ & 88.2 & $4.69 \times 10^{5}$ \\
\hline 5-Nitroguaiacol & $3.49 \times 10^{-12}$ & 79.6 & $2.25 \times 10^{5}$ \\
\hline $\begin{array}{l}\text { 2,4- } \\
\text { Dinitrophenol }\end{array}$ & $0.66 \times 10^{-12}$ & 420.9 & $1.16 \times 10^{4}$ \\
\hline
\end{tabular}

145 Table S3. Ratio (W) of the rate of gas phase $\mathrm{OH}$ oxidation and the rate of aqueous phase $\mathrm{OH}$ 146 oxidation for nitrocatechol, nitroguaiacol, and dinitrophenol, as calculated from equation 5.

\begin{tabular}{|l|c|}
\hline Molecule & W (unitless) \\
\hline 4-Nitrocatechol & $1.10 \times 10^{-2}$ \\
\hline 5-Nitroguaiacol & $2.44 \times 10^{-2}$ \\
\hline 2,4-Dinitrophenol & $1.25 \times 10^{-1}$ \\
\hline
\end{tabular}

147

148 Table S4. Identified products from photo-oxidation of nitrophenols.

\begin{tabular}{|r|l|l|c|c|c|}
\hline$m / z$ & $\begin{array}{l}\text { Molecular } \\
\text { Formula } \\
\text { (anion) }\end{array}$ & Proposed Identity & \multicolumn{3}{|c|}{ Peak Time (Minutes) } \\
\cline { 3 - 6 } & Nitrocatechol & Nitroguaiacol & Dinitrophenol \\
\hline 42 & $\mathrm{NCO}$ & Isocyanic acid & 36.0 & 54.4 & 45.0 \\
\hline 46 & $\mathrm{CHO}_{2}$ & Formic acid & N/A & 19.8 & 20.3 \\
\hline 61 & $\mathrm{NO}_{2}$ & Nitrous acid & 13.7 & 25.1 & 18.8 \\
\hline & $\mathrm{CHO}_{3}$ & Carbonic acid & 47.9 & 76.3 (end) & 50.2 (end) \\
\hline
\end{tabular}




\begin{tabular}{|c|c|c|c|c|c|}
\hline 62 & $\mathrm{NO}_{3}$ & Nitric acid & 66.7 (end) & 76.3 (end) & 50.2 (end) \\
\hline 68 & $\mathrm{C}_{3} \mathrm{H}_{2} \mathrm{NO}$ & $\begin{array}{l}\text { Possible: Isocyanatoethene, } \\
\text { Isoxazole }\end{array}$ & 7.2 & 9.7 & 11.6 \\
\hline 73 & $\mathrm{C}_{2} \mathrm{HO}_{3}$ & Glyoxylic acid & 18.5 & 29.4 & 23.8 \\
\hline 75 & $\mathrm{C}_{2} \mathrm{H}_{3} \mathrm{O}_{3}$ & Glycolic acid & 26.0 & 49.7 & 28.9 \\
\hline 84 & $\mathrm{C}_{3} \mathrm{H}_{2} \mathrm{NO}_{2}$ & $\begin{array}{l}\text { Possible: Acetyl isocyanate, } \\
\text { Isoxazolone, Cyanoacetic } \\
\text { acid }\end{array}$ & 11.8 & 17.0 & 16.2 \\
\hline 88 & $\mathrm{C}_{2} \mathrm{H}_{2} \mathrm{NO}_{3}$ & Nitroethenol & 66.7 (end) & 76.3 (end) & 27.5 \\
\hline 89 & $\mathrm{C}_{2} \mathrm{HO}_{4}$ & Oxalic acid & 48.4 & 76.3 (end) & 50.2 (end) \\
\hline 93 & $\mathrm{C}_{6} \mathrm{H}_{5} \mathrm{O}$ & Phenol & N/A & N/A & N/A \\
\hline 96 & $\mathrm{C}_{4} \mathrm{H}_{2} \mathrm{NO}_{2}$ & $\begin{array}{l}\text { Possible: Nitrosofuran, } \\
\text { Cyanoacrylic acid }\end{array}$ & 7.4 & 11.2 & 10.7 \\
\hline 102 & $\mathrm{C}_{3} \mathrm{H}_{4} \mathrm{NO}_{3}$ & $\begin{array}{l}\text { Possible: Nitroacetone, } \\
\text { Nitropropanal }\end{array}$ & 9.1 & 18.1 & 13.9 \\
\hline 103 & $\mathrm{C}_{3} \mathrm{H}_{3} \mathrm{O}_{4}$ & Malonic acid & 25.6 & 34.6 & 22.5 \\
\hline 109 & $\mathrm{C}_{6} \mathrm{H}_{5} \mathrm{O}_{2}$ & Catechol & N/A & N/A & N/A \\
\hline 111 & $\mathrm{C}_{5} \mathrm{H}_{3} \mathrm{O}_{3}$ & Furoic acid & 9.5 & 17.0 & 12.7 \\
\hline 112 & $\mathrm{C}_{4} \mathrm{H}_{2} \mathrm{NO}_{3}$ & Nitrofuran & 7.0 & 11.9 & 13.2 \\
\hline 114 & $\mathrm{C}_{4} \mathrm{H}_{4} \mathrm{NO}_{3}$ & $\begin{array}{l}\text { Possible: Nitrobutenone, } \\
\text { Nitrodihydrofuran }\end{array}$ & 8.9 & 15.7 & 15.9 \\
\hline 115 & $\mathrm{C}_{4} \mathrm{H}_{3} \mathrm{O}_{4}$ & Maleic acid & 12.0 & 22.2 & 17.2 \\
\hline 116 & $\mathrm{C}_{3} \mathrm{H}_{2} \mathrm{NO}_{4}$ & $\begin{array}{l}\text { Possible: Nitroacrylic acid, } \\
\text { Nitromalonaldehyde }\end{array}$ & 13.8 & 23.8 & 19.0 \\
\hline 116 & $\mathrm{C}_{4} \mathrm{H}_{6} \mathrm{NO}_{3}$ & Possible: Nitrobutanone & N/A & 27.7 & N/A \\
\hline 118 & $\mathrm{C}_{3} \mathrm{H}_{4} \mathrm{NO}_{4}$ & Nitropropanoic acid & 14.3 & 23.2 & N/A \\
\hline 123 & $\mathrm{C}_{6} \mathrm{H}_{3} \mathrm{O}_{3}$ & Hydroxybenzoquinone & N/A & 4.9 & 5.3 \\
\hline 123 & $\mathrm{C}_{7} \mathrm{H}_{7} \mathrm{O}_{2}$ & Guaiacol & N/A & N/A & N/A \\
\hline
\end{tabular}




\begin{tabular}{|c|c|c|c|c|c|}
\hline 124 & $\mathrm{C}_{6} \mathrm{H}_{4} \mathrm{O}_{3}$ & Trihydroxybenzene & N/A & 6.6 & 6.2 \\
\hline 127 & $\mathrm{C}_{5} \mathrm{H}_{3} \mathrm{O}_{4}$ & $\begin{array}{l}\text { Possible: Dioxopentenoic } \\
\text { acid, Hydroxyfuroic acid }\end{array}$ & 11.0 & 17.9 & 14.7 \\
\hline 130 & $\mathrm{C}_{4} \mathrm{H}_{4} \mathrm{NO}_{4}$ & $\begin{array}{l}\text { Possible: Methyl- } \\
\text { nitroacrylic acid, } \\
\text { Hydroxyimino-oxobutanoic } \\
\text { acid }\end{array}$ & 7.4 & 20.1 & 15.7 \\
\hline 134 & $\mathrm{C}_{3} \mathrm{H}_{4} \mathrm{NO}_{5}$ & Hydroxynitropropanoic acid & 25.3 & N/A & N/A \\
\hline 138 & $\mathrm{C}_{6} \mathrm{H}_{4} \mathrm{NO}_{3}$ & Nitrophenol & N/A & N/A & N/A \\
\hline 139 & $\mathrm{C}_{6} \mathrm{H}_{3} \mathrm{O}_{4}$ & Dihydroxy-benzoquinone & 5.3 & 8.0 & 9.5 \\
\hline 139 & $\mathrm{C}_{7} \mathrm{H}_{7} \mathrm{O}_{3}$ & Methoxy-benzenediol & N/A & N/A & N/A \\
\hline 140 & $\mathrm{C}_{5} \mathrm{H}_{2} \mathrm{NO}_{4}$ & Nitrofurfual & 6.6 & 9.8 & 10.1 \\
\hline 141 & $\mathrm{C}_{5} \mathrm{HO}_{5}$ & Possible: Croconic acid & 16.8 & 22.7 & 19.8 \\
\hline 141 & $\mathrm{C}_{6} \mathrm{H}_{5} \mathrm{O}_{4}$ & $\begin{array}{l}\text { Possible: } \\
\text { Tetrahydroxybenzene, } \\
\text { Muconic acid }\end{array}$ & 13.5 & N/A & 18.3 \\
\hline 154 & $\mathrm{C}_{6} \mathrm{H}_{4} \mathrm{NO}_{4}$ & Nitrocatechol & 0 & N/A & 6.0 \\
\hline 156 & $\mathrm{C}_{7} \mathrm{H}_{8} \mathrm{O}_{4}$ & $?$ & N/A & 8.5 & $\mathrm{~N} / \mathrm{A}$ \\
\hline 158 & $\mathrm{C}_{5} \mathrm{H}_{4} \mathrm{NO}_{5}$ & $\begin{array}{l}\text { Possible: Hydroxy-nitro- } \\
\text { pentadienoic acid }\end{array}$ & N/A & 23.2 & 10.7 \\
\hline 168 & $\mathrm{C}_{6} \mathrm{H}_{2} \mathrm{NO}_{5}$ & $?$ & N/A & N/A & 7.0 \\
\hline 168 & $\mathrm{C}_{7} \mathrm{H}_{6} \mathrm{NO}_{4}$ & Nitroguaiacol & N/A & 0.0 & N/A \\
\hline 169 & $\mathrm{C}_{6} \mathrm{H}_{3} \mathrm{NO}_{5}$ & ? & 4.4 & N/A & 7.4 \\
\hline 170 & $\mathrm{C}_{6} \mathrm{H}_{4} \mathrm{NO}_{5}$ & Nitrocatechol $+\mathrm{O}$ & 5.4 & N/A & 8.7 \\
\hline 172 & $\mathrm{C}_{6} \mathrm{H}_{6} \mathrm{NO}_{5}$ & $\begin{array}{l}\text { Possible: Hydroxy- } \\
\text { nitromethyl-pyranone, } \\
\text { Methoxycarbonyl-dihydro- } \\
\text { oxazole carboxylic acid }\end{array}$ & 16.8 & 7.0 & $\mathrm{~N} / \mathrm{A}$ \\
\hline 176 & $\mathrm{C}_{8} \mathrm{H}_{4} \mathrm{~N}_{2} \mathrm{O}_{3}$ & $?$ & N/A & 21.4 & $\mathrm{~N} / \mathrm{A}$ \\
\hline
\end{tabular}




\begin{tabular}{|c|c|c|c|c|c|}
\hline 181 & $\mathrm{C}_{3} \mathrm{H}_{5} \mathrm{~N}_{2} \mathrm{O}_{7}$ & Possible: Dinitroglycerin & N/A & 11.6 & 6.3 \\
\hline 181 & $\mathrm{C}_{9} \mathrm{H}_{9} \mathrm{O}_{4}$ & $\begin{array}{l}\text { Possible: } \\
\text { Dihydroxybenzenepropionic } \\
\text { acid }\end{array}$ & 4.6 & N/A & $\mathrm{N} / \mathrm{A}$ \\
\hline 183 & $\mathrm{C}_{6} \mathrm{H}_{3} \mathrm{~N}_{2} \mathrm{O}_{5}$ & Dinitrophenol & $\mathrm{N} / \mathrm{A}$ & 5.3 & 0.0 \\
\hline 184 & $\mathrm{C}_{7} \mathrm{H}_{6} \mathrm{NO}_{5}$ & Nitroguaiacol $+\mathrm{O}$ & N/A & 6.9 & $\mathrm{~N} / \mathrm{A}$ \\
\hline 185 & $\mathrm{C}_{10} \mathrm{H}_{5} \mathrm{~N}_{2} \mathrm{O}_{2}$ & $?$ & N/A & 7.2 & $\mathrm{~N} / \mathrm{A}$ \\
\hline 186 & $\mathrm{C}_{6} \mathrm{H}_{4} \mathrm{NO}_{6}$ & Nitrocatechol $+2 \mathrm{O}$ & 8.2 & $\mathrm{~N} / \mathrm{A}$ & $\mathrm{N} / \mathrm{A}$ \\
\hline 199 & $\mathrm{C}_{6} \mathrm{H}_{3} \mathrm{~N}_{2} \mathrm{O}_{6}$ & Dinitrophenol $+\mathrm{O}$ & $\mathrm{N} / \mathrm{A}$ & $\mathrm{N} / \mathrm{A}$ & 6.8 \\
\hline 200 & $\mathrm{C}_{7} \mathrm{H}_{6} \mathrm{NO}_{6}$ & Nitroguaiacol $+2 \mathrm{O}$ & $\mathrm{N} / \mathrm{A}$ & 10.3 & $\mathrm{~N} / \mathrm{A}$ \\
\hline 202 & $\mathrm{C}_{6} \mathrm{H}_{4} \mathrm{NO}_{7}$ & Nitrocatechol +30 & 8.2 & N/A & $\mathrm{N} / \mathrm{A}$ \\
\hline 215 & $\mathrm{C}_{6} \mathrm{H}_{3} \mathrm{~N}_{2} \mathrm{O}_{7}$ & Dinitrophenol $+2 \mathrm{O}$ & $\mathrm{N} / \mathrm{A}$ & $\mathrm{N} / \mathrm{A}$ & 9.9 \\
\hline 216 & $\mathrm{C}_{7} \mathrm{H}_{6} \mathrm{NO}_{7}$ & Nitroguaiacol +30 & $\mathrm{~N} / \mathrm{A}$ & 15.0 & $\mathrm{~N} / \mathrm{A}$ \\
\hline 218 & $\mathrm{C}_{6} \mathrm{H}_{4} \mathrm{NO}_{8}$ & Nitrocatechol $+4 \mathrm{O}$ & 5.3 & $\mathrm{~N} / \mathrm{A}$ & $\mathrm{N} / \mathrm{A}$ \\
\hline 231 & $\mathrm{C}_{6} \mathrm{H}_{3} \mathrm{~N}_{2} \mathrm{O}_{8}$ & Dinitrophenol $+3 \mathrm{O}$ & $\mathrm{N} / \mathrm{A}$ & $\mathrm{N} / \mathrm{A}$ & 11.3 \\
\hline 232 & $\mathrm{C}_{7} \mathrm{H}_{6} \mathrm{NO}_{8}$ & Nitroguaiacol $+4 \mathrm{O}$ & $\mathrm{N} / \mathrm{A}$ & 14.7 & $\mathrm{~N} / \mathrm{A}$ \\
\hline 234 & $\mathrm{C}_{6} \mathrm{H}_{4} \mathrm{NO}_{9}$ & Nitrocatechol $+5 \mathrm{O}$ & 6.6 & $\mathrm{~N} / \mathrm{A}$ & $\mathrm{N} / \mathrm{A}$ \\
\hline 247 & $\mathrm{C}_{6} \mathrm{H}_{3} \mathrm{~N}_{2} \mathrm{O}_{9}$ & Dinitrophenol +40 & N/A & N/A & $\mathrm{N} / \mathrm{A}$ \\
\hline 248 & $\mathrm{C}_{7} \mathrm{H}_{6} \mathrm{NO}_{9}$ & Nitroguaiacol $+5 \mathrm{O}$ & $\mathrm{N} / \mathrm{A}$ & $\mathrm{N} / \mathrm{A}$ & $\mathrm{N} / \mathrm{A}$ \\
\hline 263 & $\mathrm{C}_{6} \mathrm{H}_{3} \mathrm{~N}_{2} \mathrm{O}_{10}$ & Dinitrophenol +50 & N/A & N/A & $\mathrm{N} / \mathrm{A}$ \\
\hline
\end{tabular}




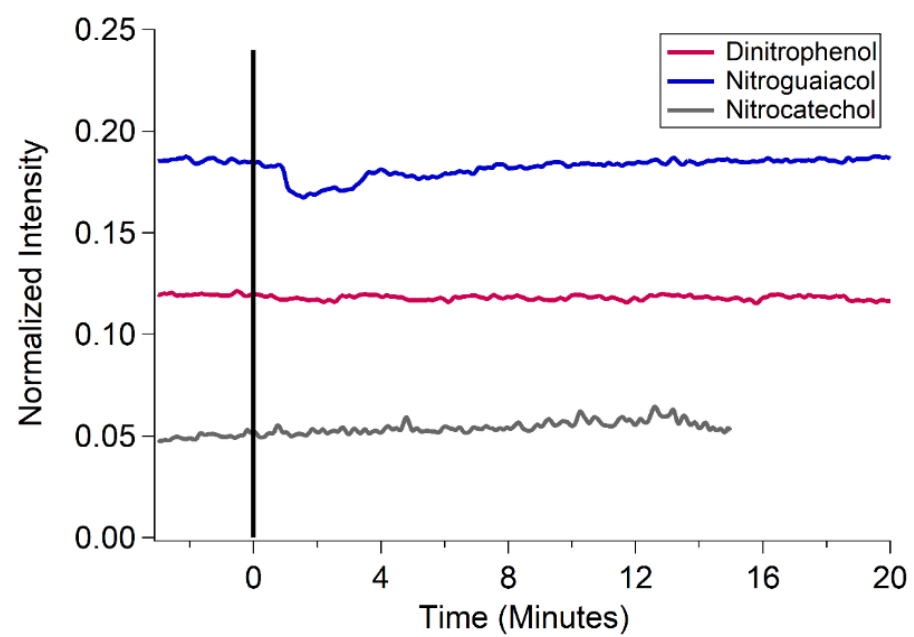

151 Figure S6. Nitrophenol signals as a function of time exposed to the UV lamp (254 nm) used in 152 photo-oxidation experiments. At time $=0$ minutes, the lamp was turned on. Direct photolysis was 153 not observed under these conditions.

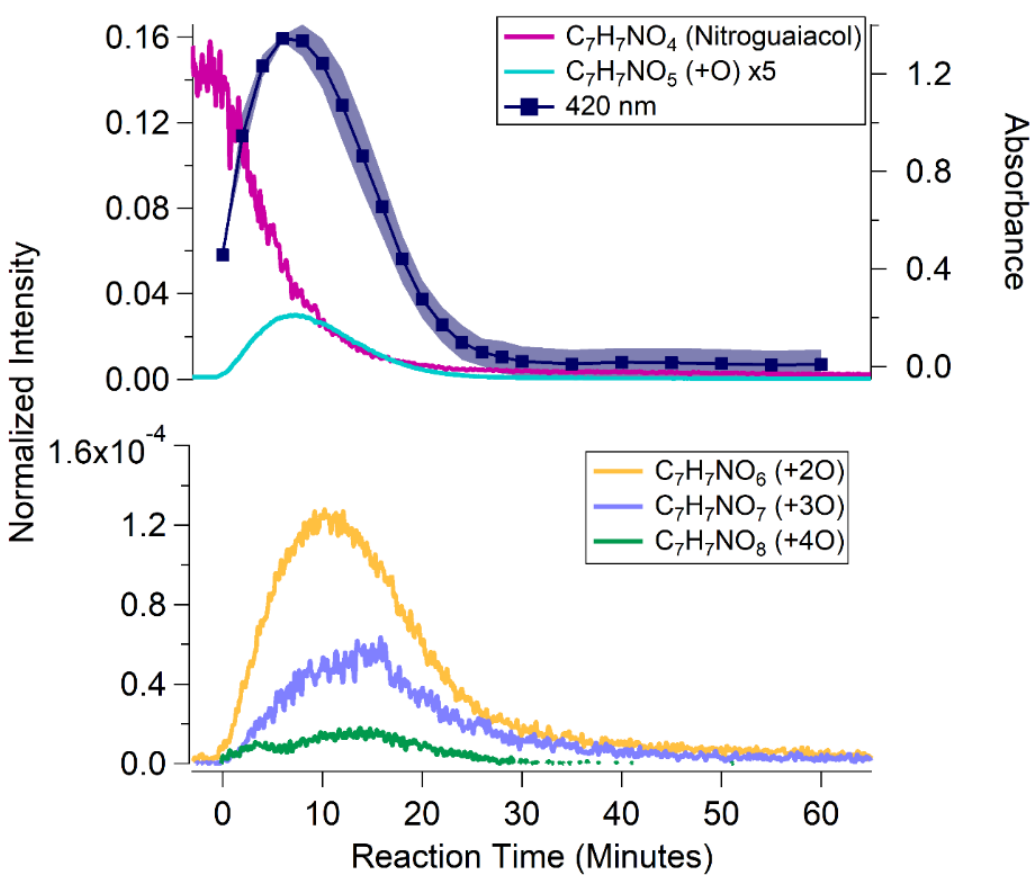

155 Figure S7. Decay of nitroguaiacol and formation of functionalization products (+O products) as a 156 function of reaction time from photo-oxidation of nitroguaiacol. The signal from each molecule is 157 normalized to the acetate reagent ion to give the normalized intensity (left axes). The absorption 158 at $420 \mathrm{~nm}$ is reproduced from Figure 2 and overlaid in the top panel (right axis) for comparison 159 to reaction products. 


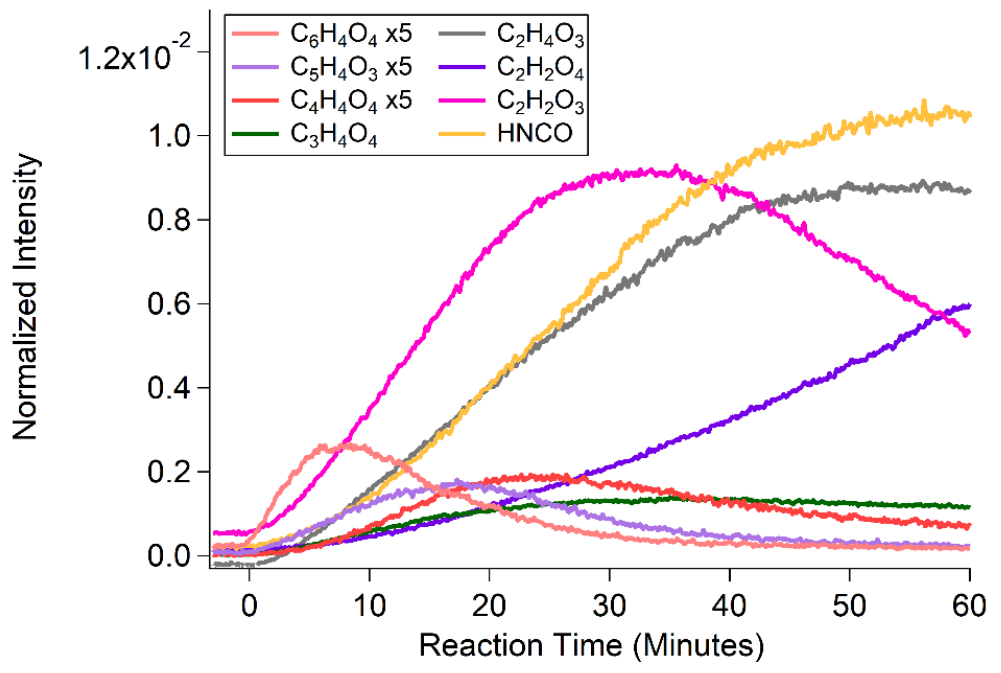

161 Figure S8. Formation of fragmentation products as a function of reaction time from the photo162 oxidation of nitroguaiacol. The signal from each molecule is normalized to the acetate reagent ion 163 to give the normalized intensity.

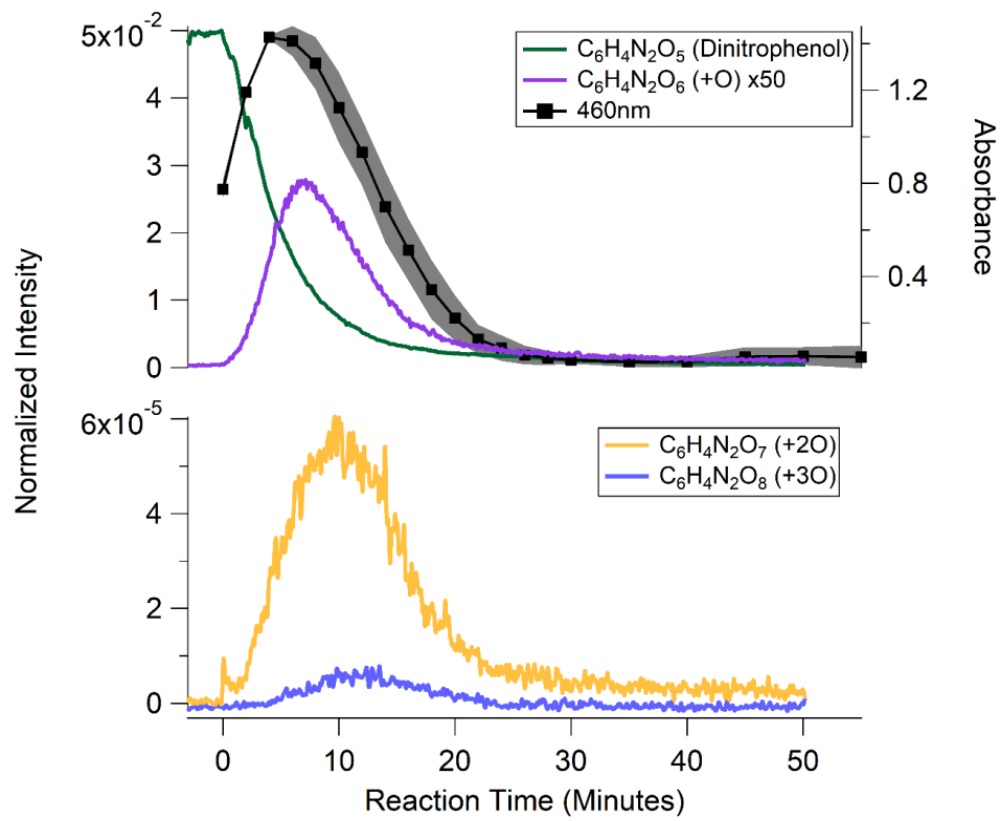

165 Figure S9. Decay of dinitrophenol and formation of functionalization products ( $+\mathrm{O}$ products) as 166 a function of reaction time from photo-oxidation of dinitrophenol. The signal from each molecule 167 is normalized to the acetate reagent ion to give the normalized intensity (left axes). The absorption 168 at $460 \mathrm{~nm}$ is reproduced from Figure 2 and overlaid in the top panel for comparison to reaction 169 products (right axis). 


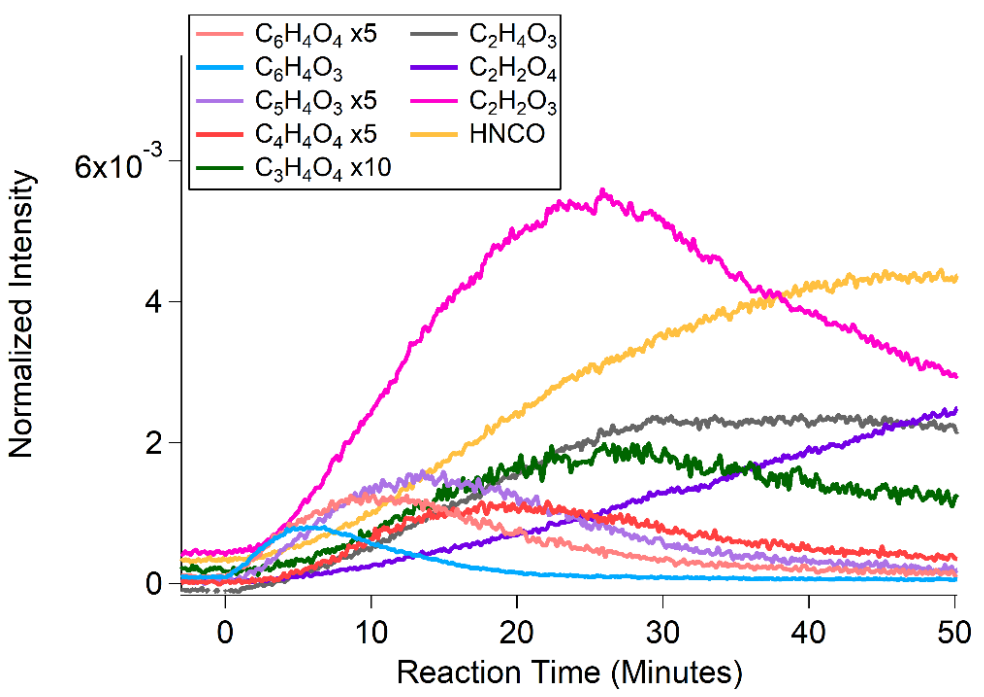

171 Figure S10. Formation of fragmentation products as a function of reaction time from the photo172 oxidation of dinitrophenol. The signal from each molecule is normalized to the acetate reagent ion 173 to give the normalized intensity.

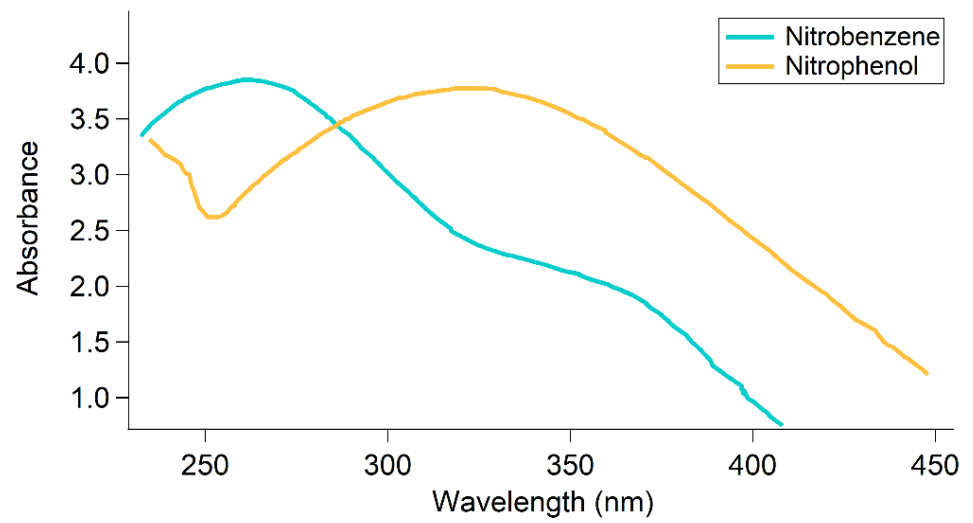

175 Figure S11. Comparison of the UV-visible absorbance spectrum of nitrobenzene and nitrophenol, 176 showing the effect of an added hydroxyl group. Data obtained from the NIST chemistry WebBook 177 http://webbook.nist.gov/chemistry/. 


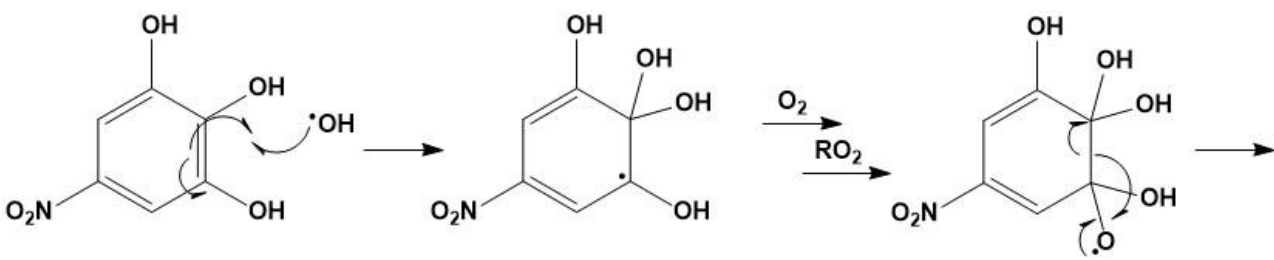<smiles>O=C(O)/C=C(\C=C(\O)C(=O)O)C(=O)O</smiles>

Figure S12. Proposed $\mathrm{OH}$-initiated ring opening mechanism for a nitrocatechol oxidation product.<smiles>O=[N+]([O-])c1cc(O)c(O)c(O)c1</smiles><smiles>O=[N+]([O-])C1CCCCC1(O)O</smiles><smiles>O=[N+]([O-])c1cc(O)c(O)c(O)c1</smiles>

182 Figure S13. Proposed nitro-group loss mechanism by attack of OH radical at the nitro-substituted 183 carbon, shown for a nitrocatechol oxidation product.

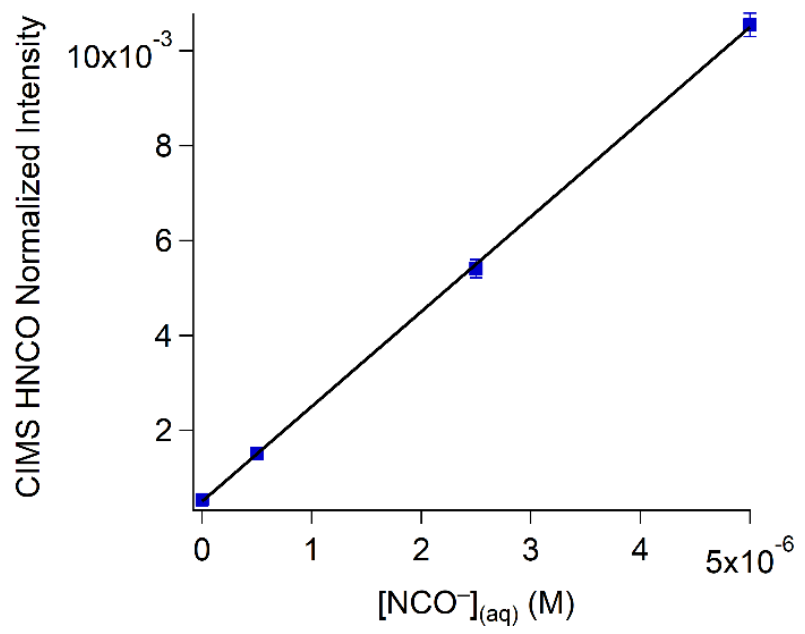

185 Figure S14. Aerosol-CIMS calibration of HNCO signal as a function of dissolved concentration 186 of isocyanate. 


\section{References}

189 (1) Herrmann, H.; Schaefer, T.; Tilgner, A.; Styler, S. A.; Weller, C.; Teich, M.; Otto, T. 190 Tropospheric Aqueous-Phase Chemistry: Kinetics, Mechanisms, and Its Coupling to a Changing Gas Phase. Chem. Rev. 2015, 115 (10), 4259-4334.

192 (2) Zhao, R.; Mungall, E. L.; Lee, A. K. Y.; Aljawhary, D.; Abbatt, J. P. D. Aqueous-Phase 193 Photooxidation of Levoglucosan - A Mechanistic Study Using Aerosol Time-of-Flight 194 Chemical Ionization Mass Spectrometry (Aerosol ToF-CIMS). Atmos. Chem. Phys. 2014, 195 14, 9695-9705.

196 (3) Epstein, S. A.; Nizkorodov, S. A. A Comparison of the Chemical Sinks of Atmospheric Organics in the Gas and Aqueous Phase. Atmos. Chem. Phys. 2012, 12, 8205-8222. 